\title{
Upgraded HFIR Fuel Element Welding System
}

February 26, 2010

\author{
Prepared by
}

J. D. Sease

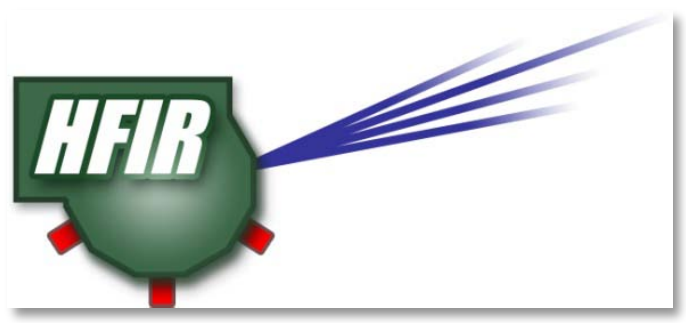




\title{
DOCUMENT AVAILABILITY
}

Reports produced after January 1, 1996, are generally available free via the U.S. Department of Energy (DOE) Information Bridge.

Web site http://www.osti.gov/bridge

Reports produced before January 1, 1996, may be purchased by members of the public from the following source.

\author{
National Technical Information Service \\ 5285 Port Royal Road \\ Springfield, VA 22161 \\ Telephone 703-605-6000 (1-800-553-6847) \\ TDD 703-487-4639 \\ Fax 703-605-6900 \\ E-mailinfo@ntis.gov \\ Web site http://www.ntis.gov/support/ordernowabout.htm
}

Reports are available to DOE employees, DOE contractors, Energy Technology Data Exchange (ETDE) representatives, and International Nuclear Information System (INIS) representatives from the following source.

Office of Scientific and Technical Information

P.O. Box 62

Oak Ridge, TN 37831

Telephone 865-576-8401

Fax 865-576-5728

E-mail reports@osti.gov

Web site http://www.osti.gov/contact.html

\begin{abstract}
This report was prepared as an account of work sponsored by an agency of the United States Government. Neither the United States Government nor any agency thereof, nor any of their employees, makes any warranty, express or implied, or assumes any legal liability or responsibility for the accuracy, completeness, or usefulness of any information, apparatus, product, or process disclosed, or represents that its use would not infringe privately owned rights. Reference herein to any specific commercial product, process, or service by trade name, trademark, manufacturer, or otherwise, does not necessarily constitute or imply its endorsement, recommendation, or favoring by the United States Government or any agency thereof. The views and opinions of authors expressed herein do not necessarily state or reflect those of the United States Government or any agency thereof.
\end{abstract}


Research Reactors Division

\title{
Upgraded HFIR Fuel Element Welding System
}

\author{
J. D. Sease
}

Date Published: February 2010

$$
\text { Prepared by }
$$

OAK RIDGE NATIONAL LABORATORY

Oak Ridge, Tennessee 37831-6283

managed by

UT-BATTELLE, LLC

for the

U.S. DEPARTMENT OF ENERGY

under contract DE-AC05-00OR22725 



\section{CONTENTS}

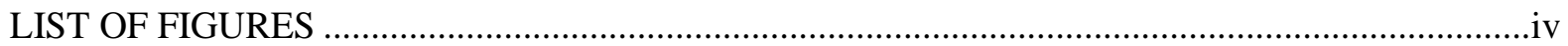

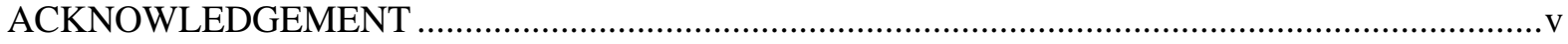

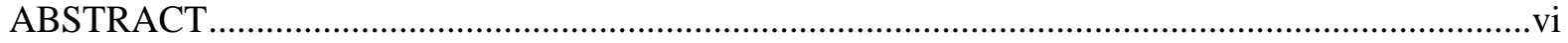

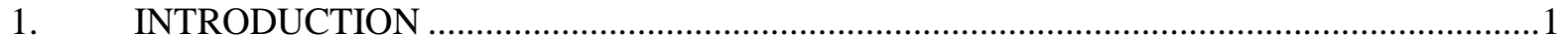

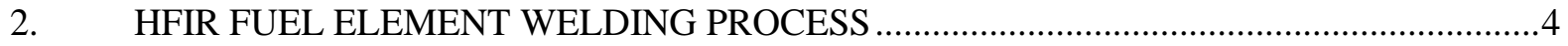

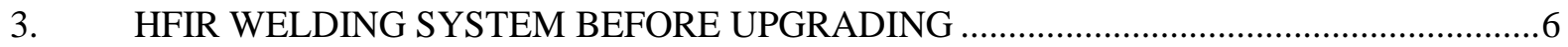

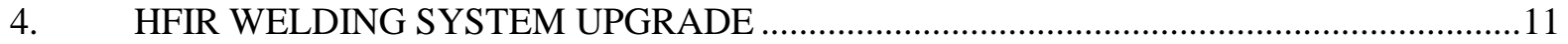

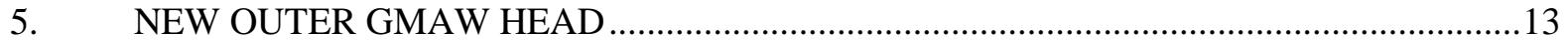

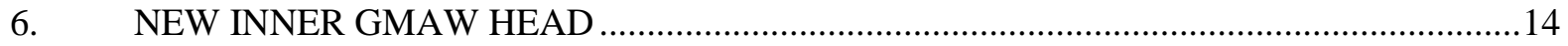

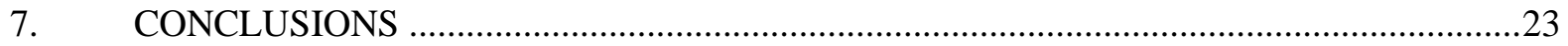

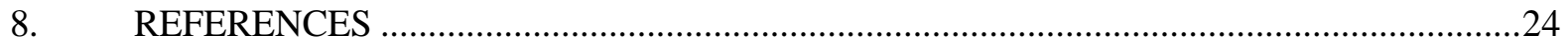





\section{LIST OF FIGURES}

Figure

1. Photograph of a completed HFIR fuel assembly

2. Typical outside diameter weld beads on a HFIR fuel element before machining

3. Inside side plate showing the slots for fuel plates on the outside and the bottom

of the weld grooves as seen from the outside

4. Outer side plate showing slots for fuel plates on the inside and the weld grooves

on the outside

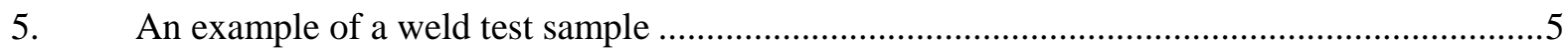

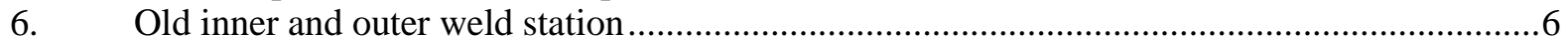

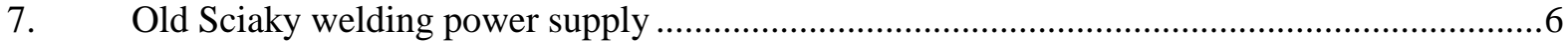

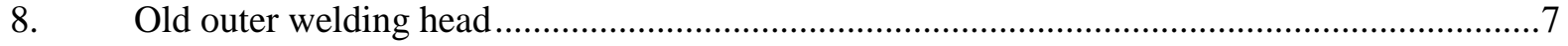

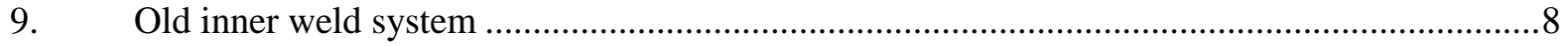

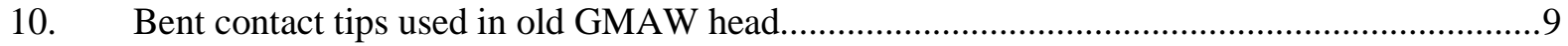

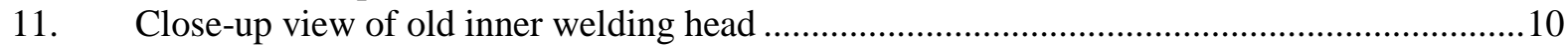

12. Schematic overview of upgraded HFIR system system.......................................................11

13. Photograph of the upgraded HFIR welding system as installed at the B\&W/

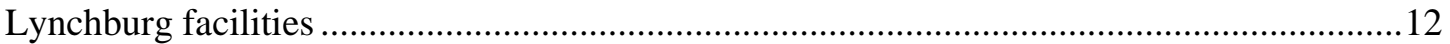

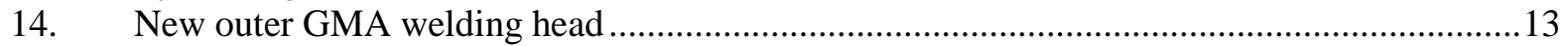

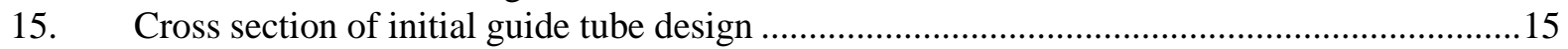

16. Guide tube design showing pull assist disengaged ..........................................................16

17. Top views of guide tube design with protective cover removed ..........................................17

18. Top view of contoured guide tube design with protective cover removed ..............................18

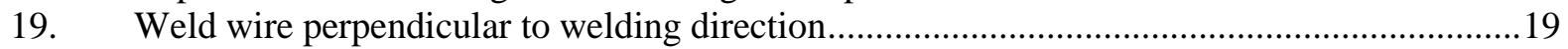

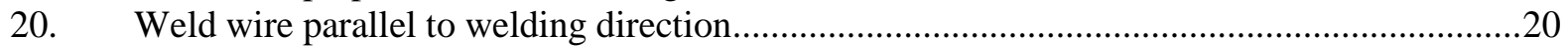

21. Jig used to shape contour of copper tubing.......................................................................22

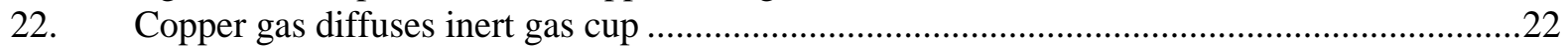

23. The standard screw threaded contact tip used in inner and outer welding torches ..................22

24. Inner welding head installed at B\&W Lynchburg, Virginia, facilities ..................................23 



\section{ACKNOWLEDGEMENTS}

The upgrading of the High Flux Isotope Reactor (HFIR) fuel element welding system required the work of many at the Babcock \& Wilcox Company (B\&W), Advanced Manufacturing Engineering Technologies, Inc. (AMET), and Oak Ridge National Laboratory (ORNL) over the course of approximately two years from the preparation of the technical requirements specification through the acceptance and qualification testing of the upgraded welding system at Lynchburg, Virginia. At B\&W, the preparation of the technical requirements was the responsibility of Mike Nilles with principle input from Tim Saloka. Tim Saloka and Randy Tuck were present at the factory acceptance testing at AMET. Steve Scoles prepared the initial acceptance and qualification test plans and was present at the initial factor acceptance testing at AMET. Tim Faix and Scott Nielzialek were responsible for the installation of the upgraded welding system at B\&W's facilities at Lynchburg, Virginia. The weld testing of the upgraded welding system at Lynchburg was performed by Randy Tuck and Kenric Burgess. The final qualification test plan and qualification tests were performed by Jared Wight.

At AMET, those involved in the successful upgrading of the HFIR welding system project included Crag Dees, Tom Whipple, Jon Sosalla, Tom Scott, Jason Williams, Thad Skinner, Stacey Dexter, Roberto Moreno, Dave P'Pool, Scott Parkinson, Dave Stompro, and Don Schwemmer. AMET was most responsive in resolving the problems encountered in developing the inner welding head.

At ORNL, Dan Pinkston was involved in all phases of procuring the upgraded HFIR welding system. Dan worked with Steve Scoles in developing the factory acceptance and qualifications test plans and procured the test hardware used in the factory acceptance testing. My thanks to Mary Wells who worked with me on the numerous iterations required to prepare and edit this document. My thanks also to David Moses and Trent Primm for editing this report. 



\begin{abstract}
The welding of aluminum-clad fuel plates into aluminum alloy 6061 side plate tubing is a unique design feature of the High Flux Isotope Reactor (HFIR) fuel assemblies as 101 full-penetration circumferential gas metal arc welds (GMAW) are required in the fabrication of each assembly. In a HFIR fuel assembly, 540 aluminum-clad fuel plates are assembled into two nested annular fuel elements $610 \mathrm{~mm}$ (24-inches) long. The welding process for the HFIR fuel elements was developed and qualified in the early 1960's and about 450 HFIR fuel assemblies have been successfully welded. In recent years because of the degradation of the electronic and mechanical components in the old HFIR welding system, reportable defects in plate attachment or adapter welds have been present in almost all completed fuel assemblies. In October 2008, a contract was awarded to AMET, Inc., of Rexburg, Idaho, to replace the old welding equipment with standard, commercially available welding components to the maximum extent possible while maintaining the qualified HFIR welding process. The upgraded HFIR welding system represents a major improvement in the welding system used in welding HFIR fuel elements for the previous 40 years. In this upgrade, the new inner GMAW torch is a significant advancement over the original inner GMAW torch. The innovative breakthrough in the new inner welding torch design is the way the direction of the cast in the $0.762 \mathrm{~mm}(0.030$-inch) diameter aluminum weld wire is changed so that the weld wire emerging from the contact tip is straight in the plane perpendicular to the welding direction without creating any significant drag resistance in the feeding of the weld wire.
\end{abstract}





\section{INTRODUCTION}

The welding of fuel plates into side plate tubing is a unique design feature of the HFIR nuclear fuel assembly. The cladding and structural material used in a HFIR fuel assembly is aluminum alloy 6061. In a HFIR fuel assembly, 540 fuel plates are assembled into two nested annular fuel elements $~ 610 \mathrm{~mm}$ (24inches) long. A complete HFIR fuel assembly showing the inner and outer fuel elements are shown in Fig. 1.

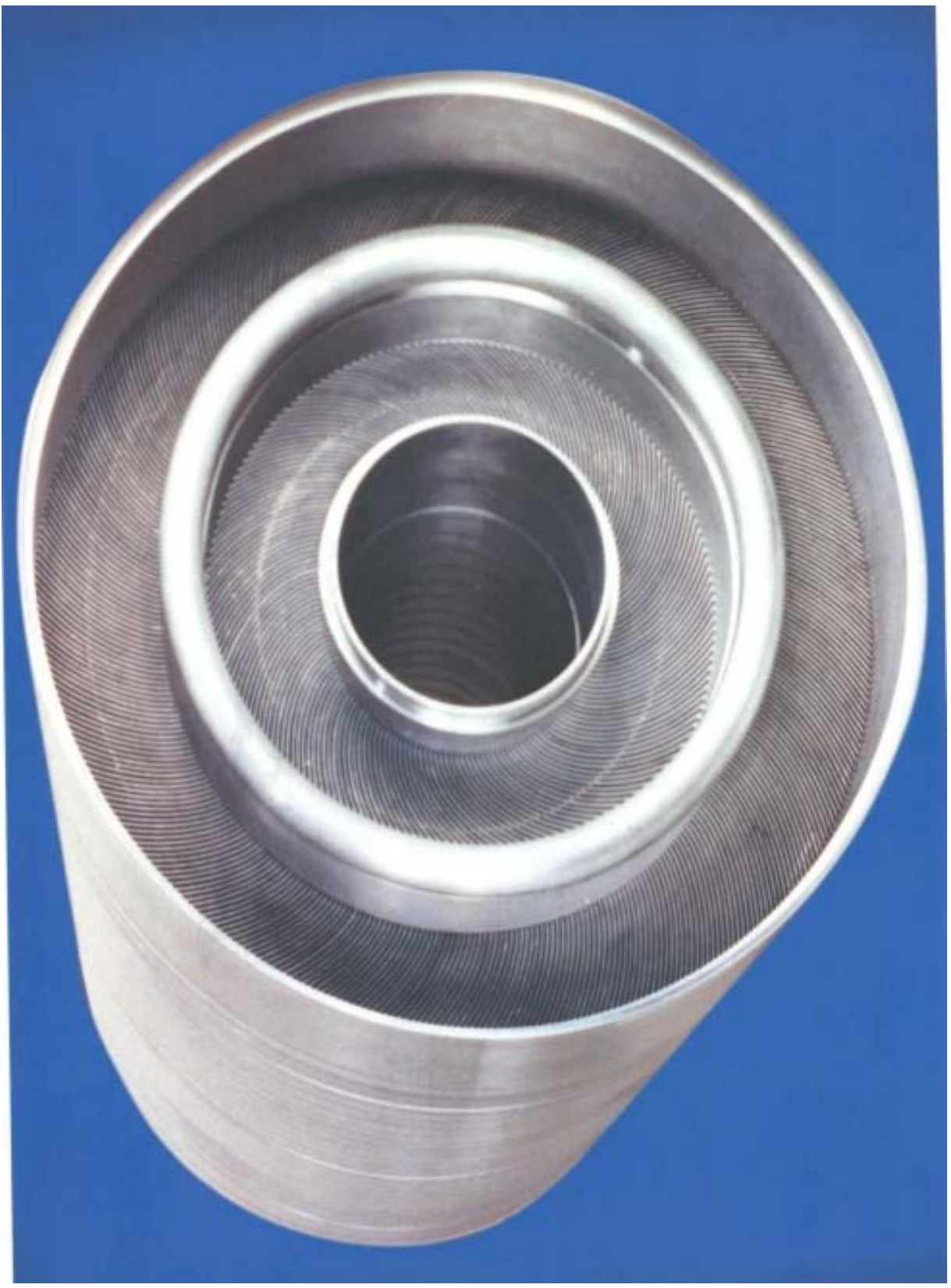

Fig. 1. Photograph of a completed HFIR fuel assembly. 
The inner fuel element has an inner diameter of $~ 127 \mathrm{~mm}$ (5 inches), with an outside diameter of 280 $\mathrm{mm}$ (11-inches) diameter and contains 171 fuel plates. The outer fuel element has an inner diameter of $\sim 292 \mathrm{~mm}$ (11.5 inches), an outside diameter of $\sim 432 \mathrm{~mm}$ (17 inches), and contains 369 fuel plates. Each HFIR fuel assembly costs more than one million dollars to fabricate and $\sim 7$ fuel assemblies are consumed each year in operating the reactor. In the fabrication of these nuclear fuel assemblies, welding is a major step as 101 full-penetration circumferential gas metal arc welds (GMAW) ${ }^{1}$ are required in the fabrication of each assembly. Typical weld beads made on the outside diameter of HFIR fuel elements before machining are shown in Fig. 2. Also shown are the weld preparation grooves used for these welds. The weld beads on the inner diameter are comparable. As shown, weld metal is a major component in the machined side plates in completed HFIR fuel elements.

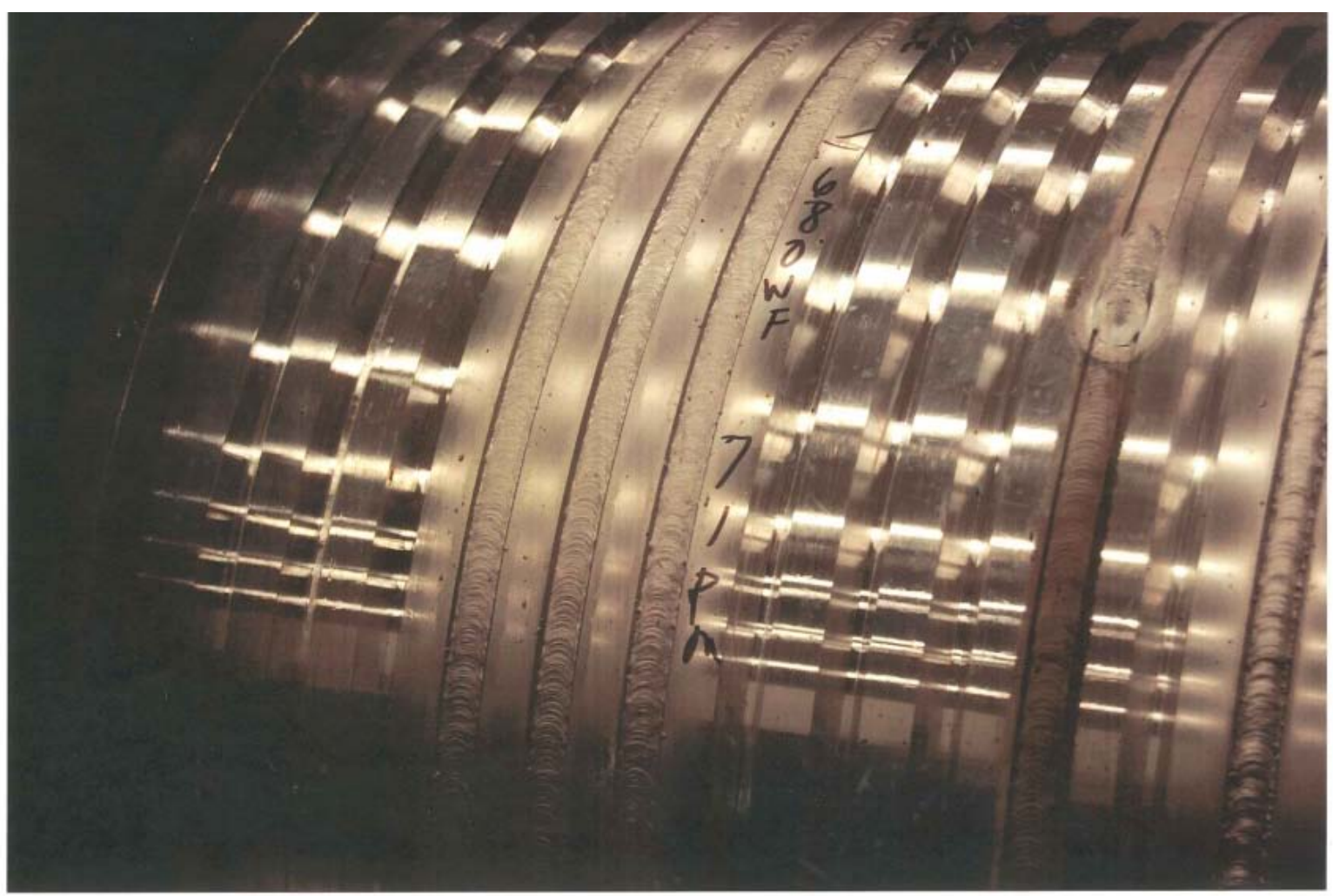

Fig. 2. Typical outside diameter weld beads on a HFIR fuel element before machining

In a HFIR fuel element, each 1.27 mm-thick (0.050 inch) fuel plate is attached by a "spot” weld, on both edges, at one-inch intervals along the $610 \mathrm{~mm}$ (24 inches) length of the fuel element. The fuel plates are contained in two $\sim 6.4 \mathrm{~mm}$-thick (1/4-inch) aluminum tubes that form the inside and outside side plates. Each of these side plates have been slotted on one side for the fuel plates and weld groove machined into the tubing every $254 \mathrm{~mm}$ (1 inch) from the side opposite the slots. Machined inner and outer side plates for an inner fuel element are shown in Figs. 3 and 4.

The spot welds for the fuel plates contained in either the inside or outside side plate are made similarly at the root of each weld groove by making a full circumferential GMAW. Each plate attachment "spot" weld is $\sim 2.54 \mathrm{~mm}(0.100$-inch) in length to prevent the fuel plate from buckling during irradiation in the reactor.

${ }^{1}$ GMAW is a newer terminology for Metal Inert Gas Weld (MIGW). 


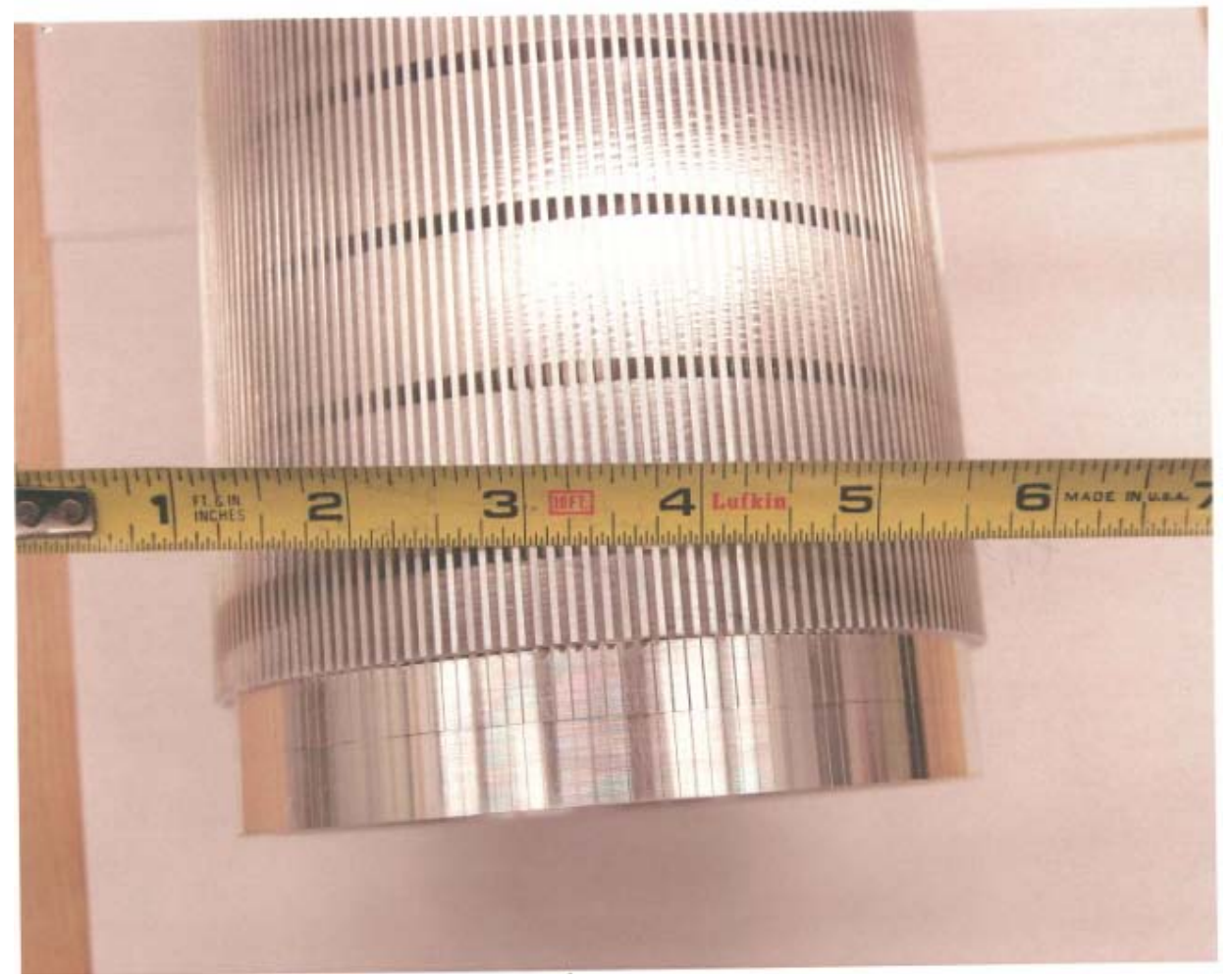

Fig. 3. Inside side plate showing the slots for fuel plates on the outside and the bottom of the weld the grooves as seen from the outside.

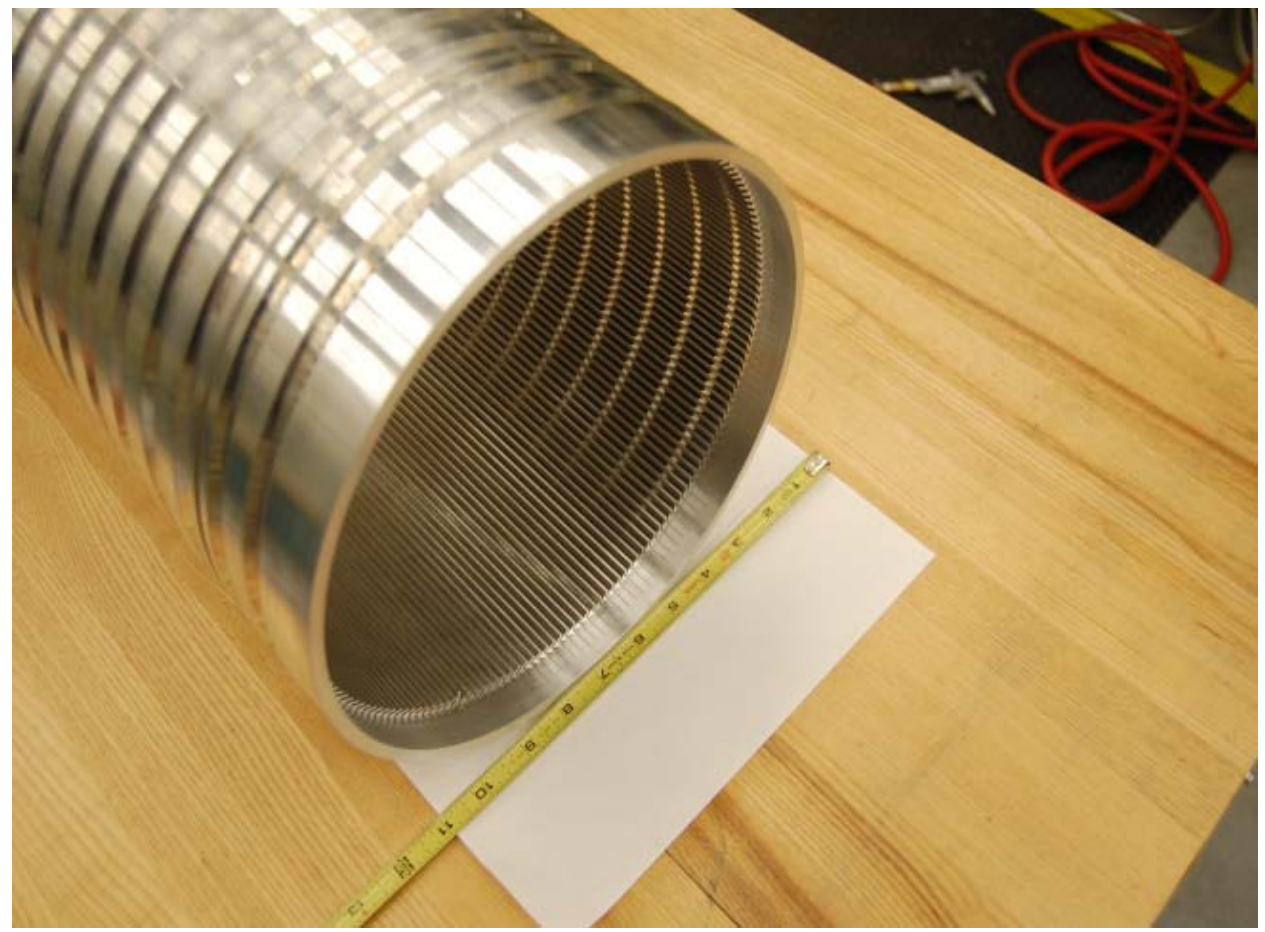

Fig. 4. Outer side plate showing slots for fuel plates on the inside and the weld grooves on the outside. 



\section{HFIR FUEL ELEMENT WELDING PROCESS}

The initial welding process for the HFIR fuel elements was developed and qualified in the early 1960's and about 450 HFIR fuel assemblies have been successfully welded. ${ }^{1,2}$ This welding process is a GMAW process using 0.030-in.-diam 4043 weld wire. The nominal welding parameters for the plate attachment welds in HFIR fuel elements are shown in Table 1.

Table 1. Nominal welding parameters for fuel plate attachments welds

\begin{tabular}{l|l|c|c|c|c|c|c|c}
\hline $\begin{array}{c}\text { Side } \\
\text { plate } \\
\text { No. }\end{array}$ & $\begin{array}{c}\text { Joint } \\
\text { diameter } \\
\text { mm (in.) }\end{array}$ & $\begin{array}{c}\text { Voltage } \\
\text { volts } \\
\text { (ref.) }\end{array}$ & $\begin{array}{c}\text { Current } \\
\text { amps } \\
\text { (ref.) }\end{array}$ & $\begin{array}{c}\text { Contact } \\
\text { tip to } \\
\text { weld } \\
\text { mm (in) }\end{array}$ & $\begin{array}{c}\text { Weld wire } \\
\text { diameter } \\
\text { mm (in) }\end{array}$ & $\begin{array}{c}\text { Wire feed } \\
\text { M/sec. } \\
\text { (in/min.) }\end{array}$ & $\begin{array}{c}\text { Travel } \\
\text { speed } \\
\text { mm/sec. } \\
\text { (in/min.) }\end{array}$ & $\begin{array}{c}\text { Duration } \\
\text { seconds }\end{array}$ \\
\hline 1 & $130(5.1)$ & 20 & 135 & $15.9(5 / 8)$ & $7.62(.030)$ & $0.25(580)$ & $5.2(12.3)$ & 75 \\
\hline 2 & $267(10.5)$ & 20 & 135 & $6.35(1 / 4)$ & $7.62(.030)$ & $0.22(530)$ & $3.3(7.8)$ & 260 \\
\hline 3 & $284(11.2)$ & 21 & 155 & $15.9(5 / 8)$ & $7.62(.030)$ & $0.28(670)$ & $4.4(10.5)$ & 200 \\
\hline 4 & $434(17.1)$ & 21 & 155 & $6.35(1 / 4)$ & $7.62(.030)$ & $\mathbf{0 . 2 7}(640)$ & $3.4(8.1)$ & 400 \\
\hline
\end{tabular}

In the development of the welding process, major concerns were maintaining the channel spacing between plates in the assembled element and the penetration of the plate attachment welds into the fuel meat sections of the fuel plates. These concerns undoubtedly influenced the selection of the specific welding process parameters used. Historically, the single pass welding process with the small diameter weld wire $0.762 \mathrm{~mm}(0.030 \mathrm{inch})$ at wire feed rates of up to $\sim 0.3 \mathrm{~m} / \mathrm{s}(700 \mathrm{inch} / \mathrm{min})$ has been a difficult process to control. Welding on the outside of the side plates where space exists for using a conventional wire straighter, feeders and standard GMAW torch head has been relatively straight forward. The welding on the inside side plates and particularly in the smaller diameter, No. 1 side plate (the inner side plate of the inner element), has suffered more quality deficiencies than the outer side plates in fabricating HFIR fuel elements. The welding of the adapters on the end of assembled fuel elements is essentially the same as a conventional pipe weld.

The fuel plate attachment welds cannot be inspected by non destructive means and must be qualified by the use of weld test samples. The weld test samples are made from segments of side plates and small surrogate or “dummy” fuel plates. An example of a weld test sample is shown in Fig. 5.

Weld test samples are prepared before and after each fuel element plate attachment weld and subjected to a "pull test" of selected dummy fuel plates and section metallographic examination of the test sample. Welding on a fuel element cannot begin until the three pulls tests samples exceed 445 Newton (100pound pull) and the metallographic section examination is satisfactory. The 445 Newton (100-poundpull) test represents a weld attachment of the $1.27 \mathrm{~mm}$-thick (0.050 inch) fuel plate of $~ 2.54$-mm long (0.100 inch), assuming the ultimate strength of the aluminum alloy 4043 weld metal is $138 \mathrm{MPa}$ (or $\sim 20,000$ psi). The weld test sample in Fig. 5 had been "pull tested" and shows the location of three plates pulled in this test. The adapter welds are inspected by conventional radiographic techniques.

Over the course of the last decade, degradation of the electronic and mechanical components in the old HFIR welding system, the instances of reportable, non-conforming welds in completed HFIR fuel elements has increased significantly. In recent years, the rate of non-conformances had reached the point where a non-conformance report for defects in the plate attachment or adapter welds was being generated for almost every completed HFIR fuel element. 


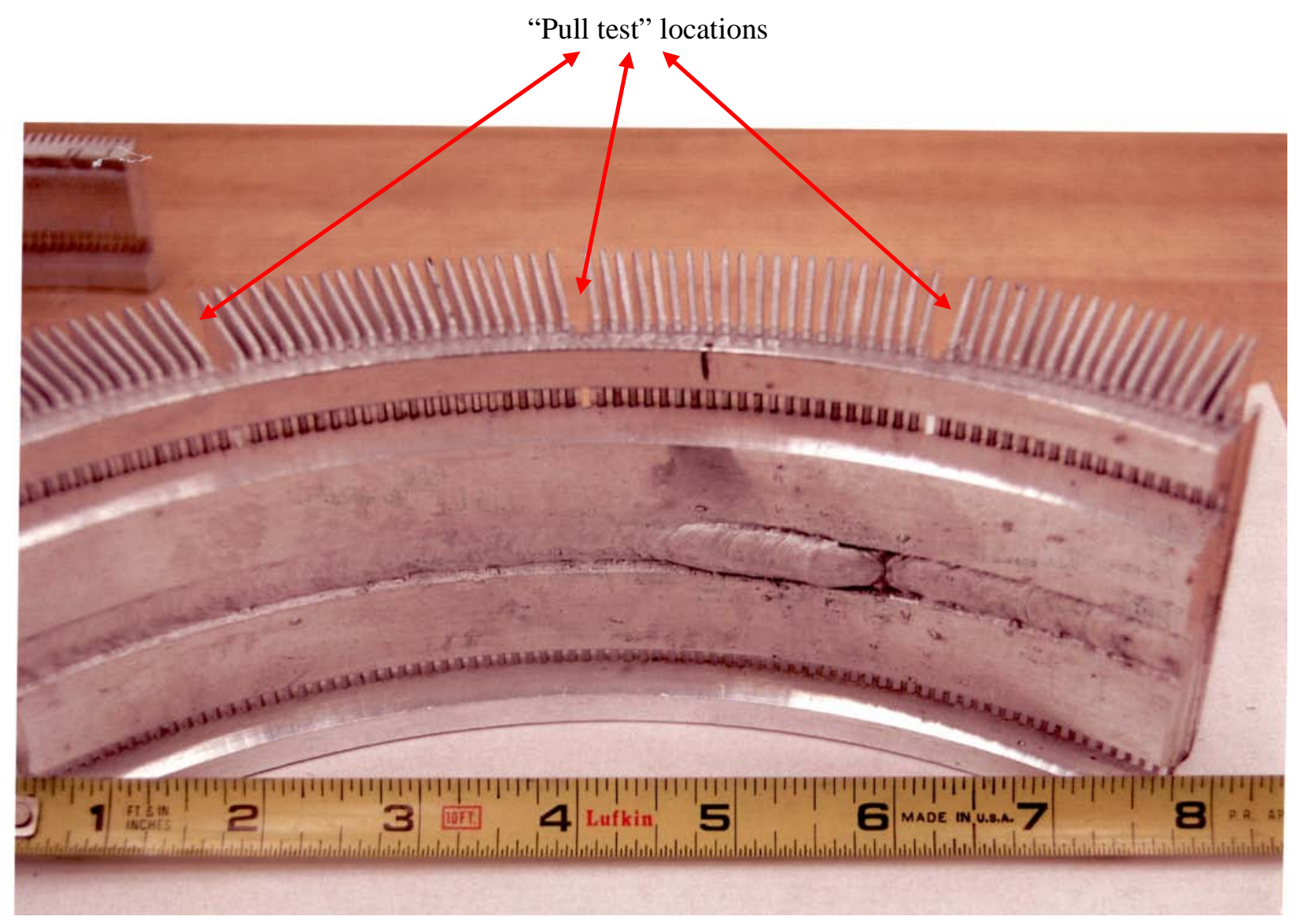

Fig. 5. An example of a weld test sample. 


\section{HFIR WELDING SYSTEM BEFORE UPGRADING}

An over view of the HFIR fuel element welding system before the upgrade is shown in Fig. 6. The welding lathe, welding heads and fixtures date back to the original design which occurred in the 1960's. The Sciaky programmable welding power supply shown in Fig. 7 dates back to the early 1980's when the welding power supply was initially upgraded.

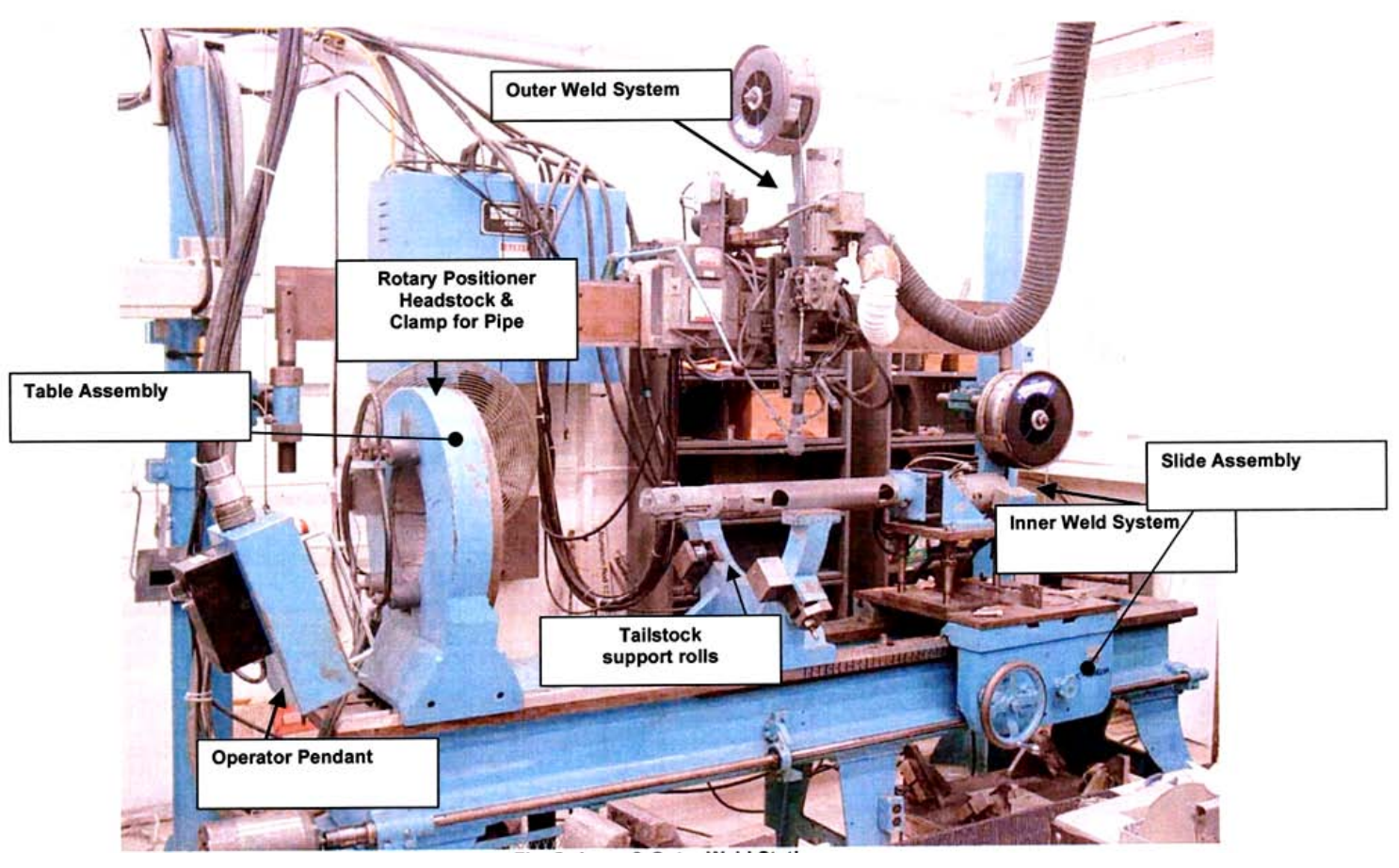

Fig. 6. Old inner and outer weld station.

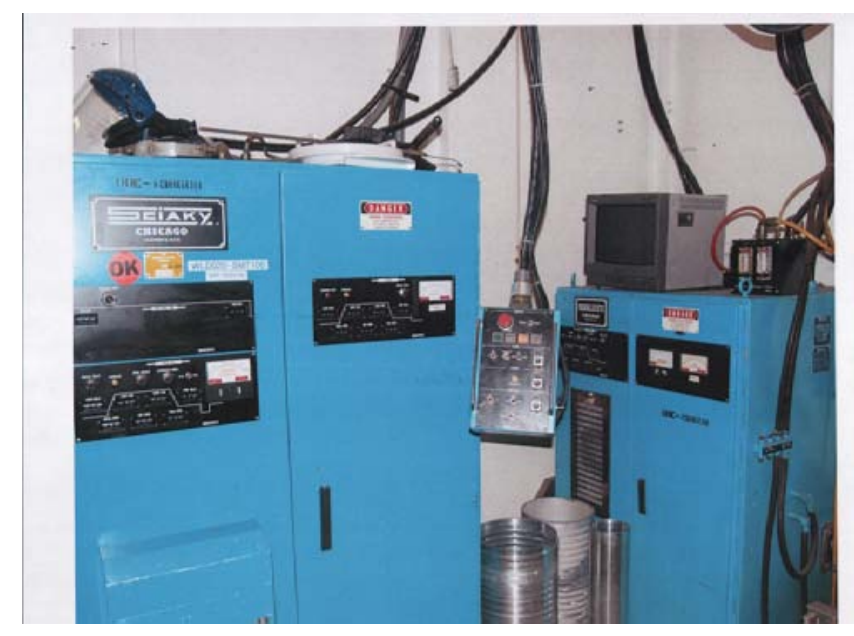

Fig. 7. Old Sciaky welding power supply. 
A detailed view of the original outer welding head is shown in Fig. 8. This welding head used a conventional wire straighter, weld wire feeders and standard GMAW head and has worked relatively reliably over the years. The upgrade outer weld head components are comparable with this original head design.

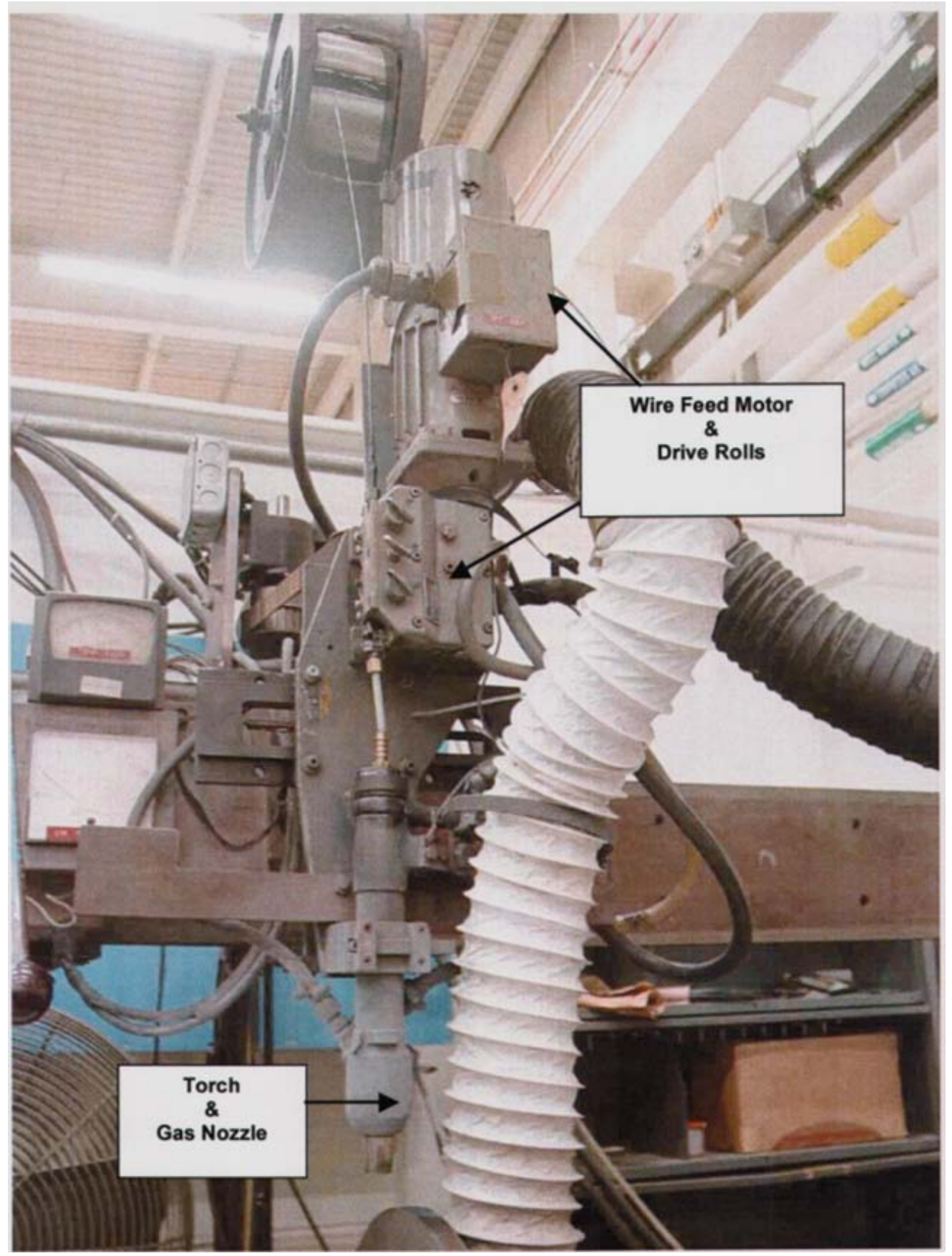

Fig. 8. Old outer welding head. 
The detail overview of the original inner welding head is shown in Fig. 9. Welding a small diameter, No. 1 side plate must be accomplished "blind" as the welder cannot observe and adjust the welding head position during welding. Because of the limited space available in the $~ 120$-mm diameter (4.75-inches) tube before final machining, a specially-designed GMAW head with a weld wire "pull" feeder incorporated into the welding head had been employed for the last $\sim 40$ years. In a GMAW, the welding wire must be straight in the plane perpendicular to the direction of the weld to control the position of the molten metal pool in the weld groove and therefore obtain a uniform groove fill and centered root penetration. The original welding head did not have a wire straightener, per se, but used a bend in the contact tip to straighten the weld wire emerging from the contact tip. The purpose of this bend in the contact tip had not been documented with the result that recent attempts to use a straight contact tip in the original weld head were unsuccessful. It had been incorrectly assumed that the purpose of the bend in the contact tip was to improve the electrical contact of the weld wire in passing through the contact tip.

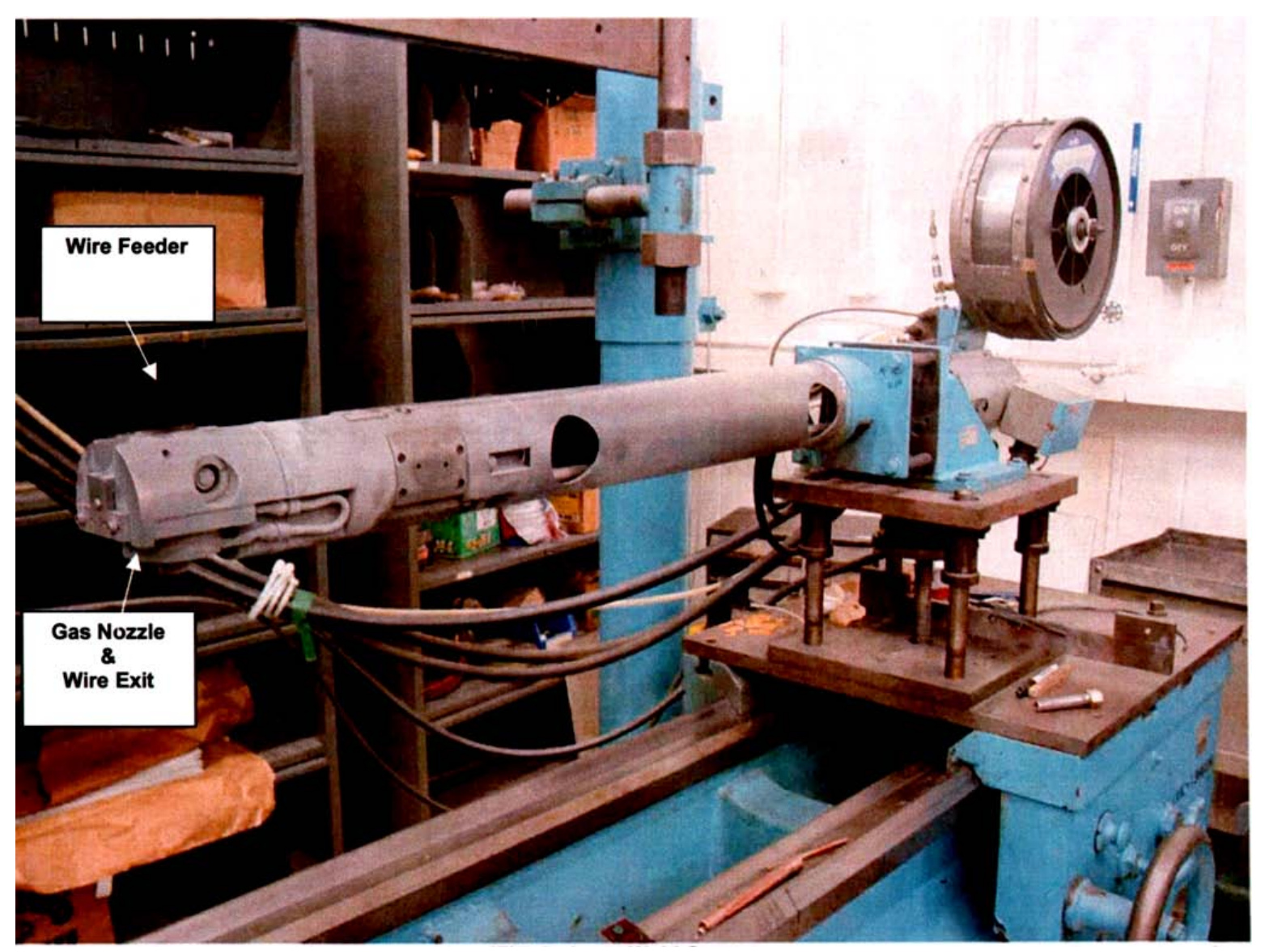

Fig. 9. Old inner weld system. 
Examples of the bent contact tips used in the original inner welding head are shown in Fig. 10. During welding, the contact tips had to be constantly checked and changed frequently. With the bent contact tip in the original inner welding head, it was always necessary to verify the straightness of the weld wire emerging from the contact tip using either a boroscope or a video camera. In most instances, adjustment of the orientation of the bent contact tip after each inspection or replacement was necessary. Establishing the correct orientation of the bent contact tip was always a difficult iterative trial and error operation and required an experienced welder to set up and to operate the inner welding head in a satisfactory manner.

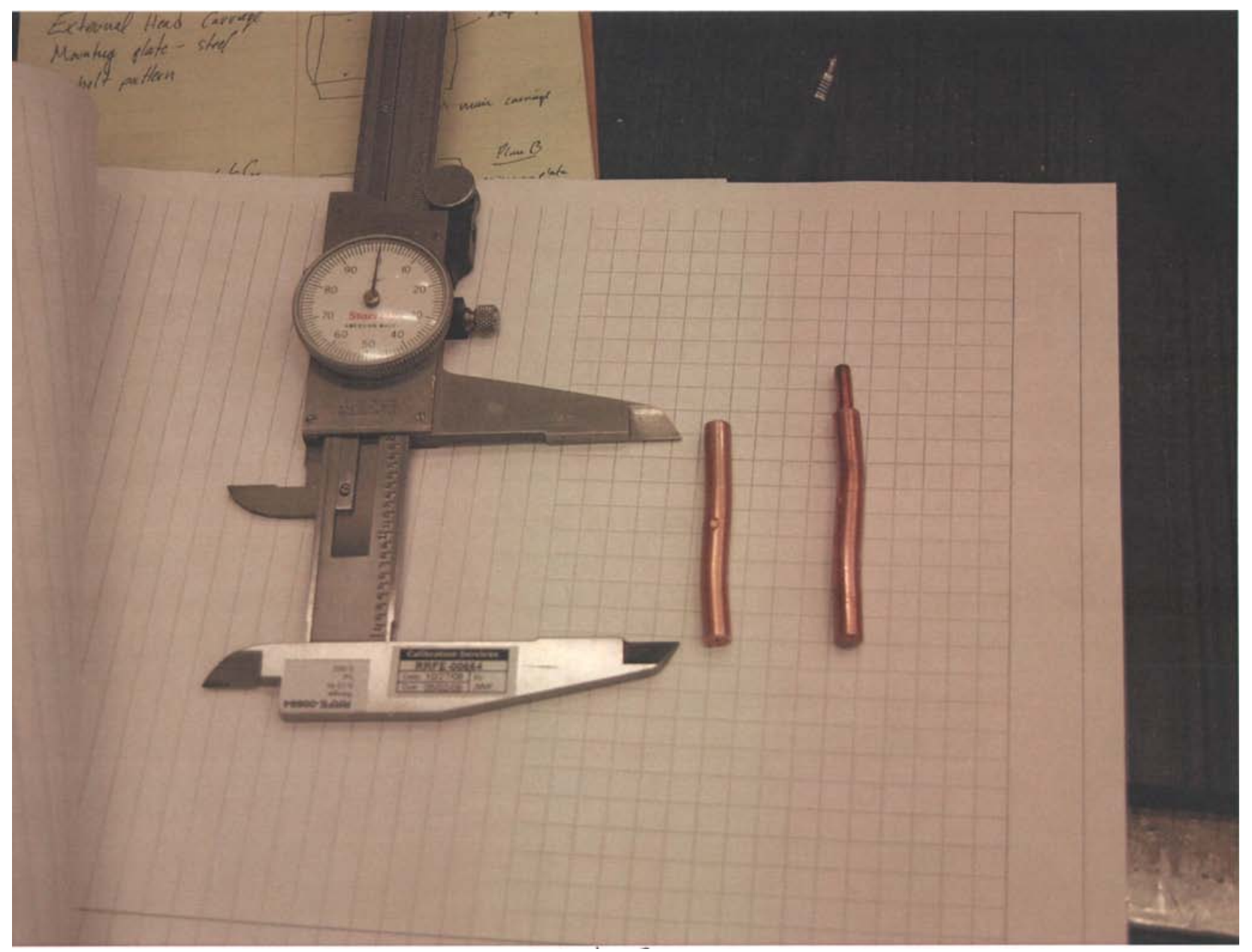

Fig. 10. Bent contact tips used in old GMAW head. 
The close-up view of the original inner head is shown in Fig. 11. The mechanical design of the pull wire feeder in the original inner welding head was complex since there were 31 separate components listed on the material list for this original inner head. The wire feeder used a belt drive mechanism in the head with the drive motor located at the rear of the support tube. The water cooled heat sink/power block and gas diffuser were made with multiple components with elastomeric "o" ring seals between components. In recently years, the original inner welding head had to be almost constantly maintained to function in a reasonably acceptable manner.

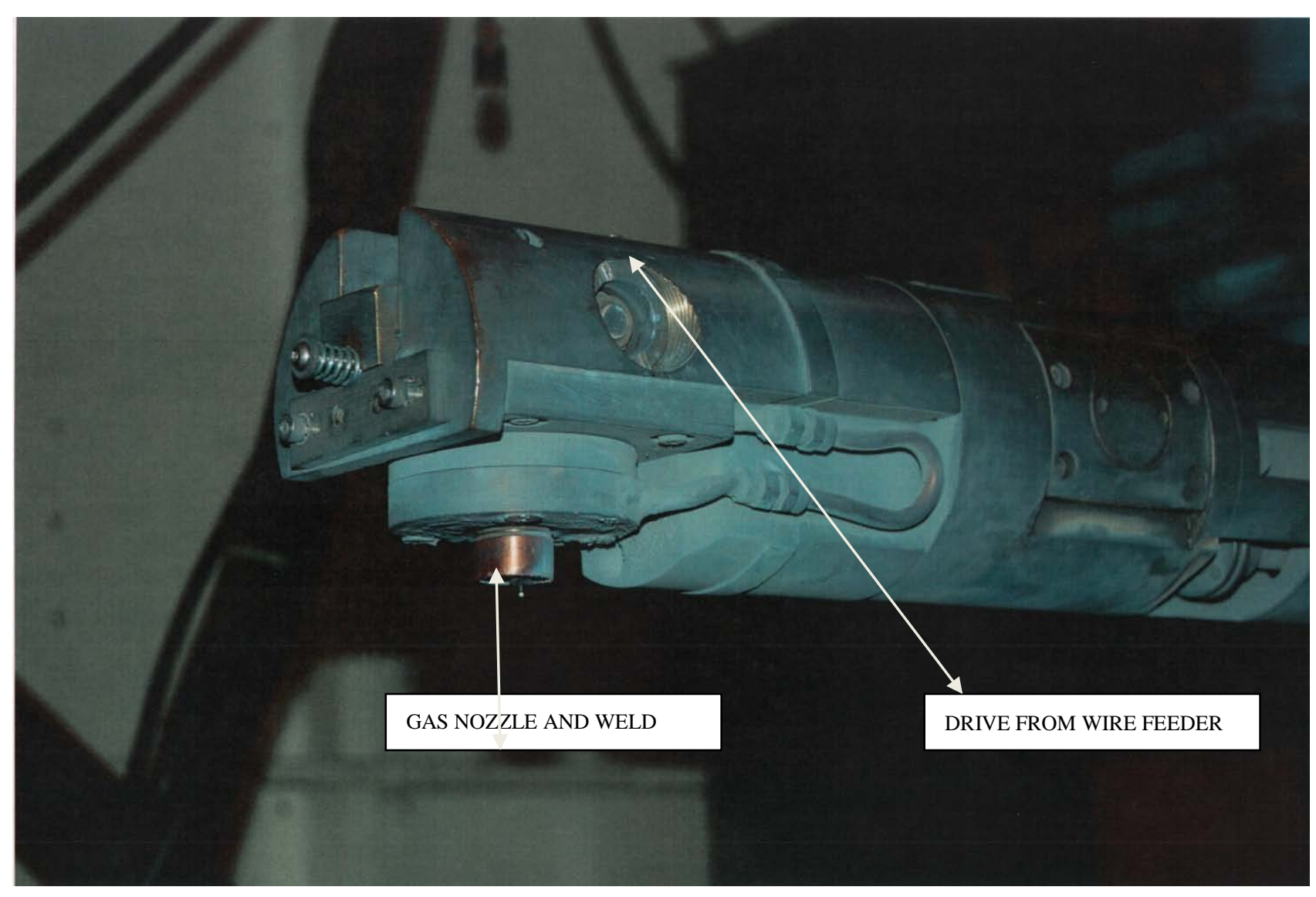

Fig. 11. Close-up view of old inner welding head 



\section{HFIR WELDING SYSTEM UPGRADE}

The upgrading of the HFIR welding system was performed under a contract awarded to AMET, Inc., of Rexburg, Idaho, in October 2008. The intent of the upgrade was to maintain the currently qualified HFIR welding processes and procedures and to replace the old equipment with standard commercially available welding components to the maximum extent possible. Because of the configuration control required for operating the HFIR nuclear reactor, the qualification of a new welding process for the HFIR fuel elements would have entailed a significant and expensive effort and was judged to be uneconomical. A schematic overview of the HFIR welding system upgrade provided by AMET is shown in Fig. 12.

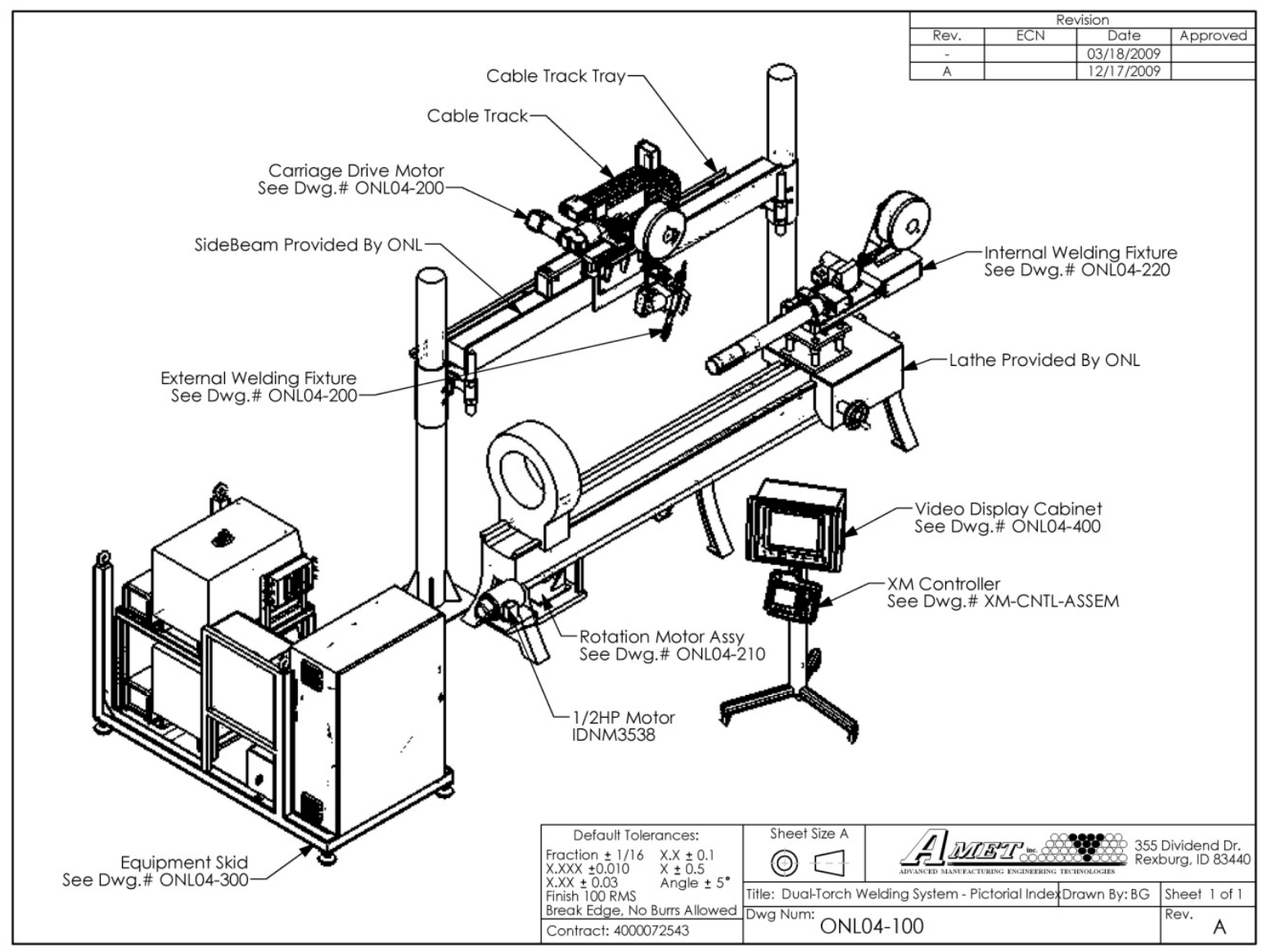

Fig. 12. Schematic overview of upgraded HFIR system system.

A summary of the technical specification used to procure the upgrade to the upgraded HFIR welding system is provided in Appendix A. Included in this upgrade was replacing the Sciaky welding power supply and controller used for both inner and outer welds with separate Lincoln model 455T-SST R power supplies and Lincoln Model XMC-1 programmed power supply controllers dedicated to either the inner and outer welding heads. The use of the separate welding power supplies and controllers was to avoid the complexity of switching between welding power supplies and controller as required in the old welding system. Standard Lincoln model S10 wire feeders were used for both the inner and the outer welding head. Extensive refurbishing of the welding lathe included replacing of the rotating motor, speed and speed/position encoder and reconditioning the head stock and electrical ground commutators. Both the inner and outer welding heads were fitted with precision position $\mathrm{x}-\mathrm{y}-\mathrm{z}$ slides and encoders for precision location of the welding head. An AMET XL controller was used to integrate the control modules for the components. The XL controller was installed into a single control pendent for both the inner and out welding head. 
The upgrading of the outer head and the other specified components went smoothly during the procurement except for design of the new inner welding head. From the beginning it was understood by ORNL, B\&W and AMET that the re design of the inner welding head would be the most difficult component to upgrade. A photograph of the installed upgraded HFIR welding system is shown in Fig. 13.

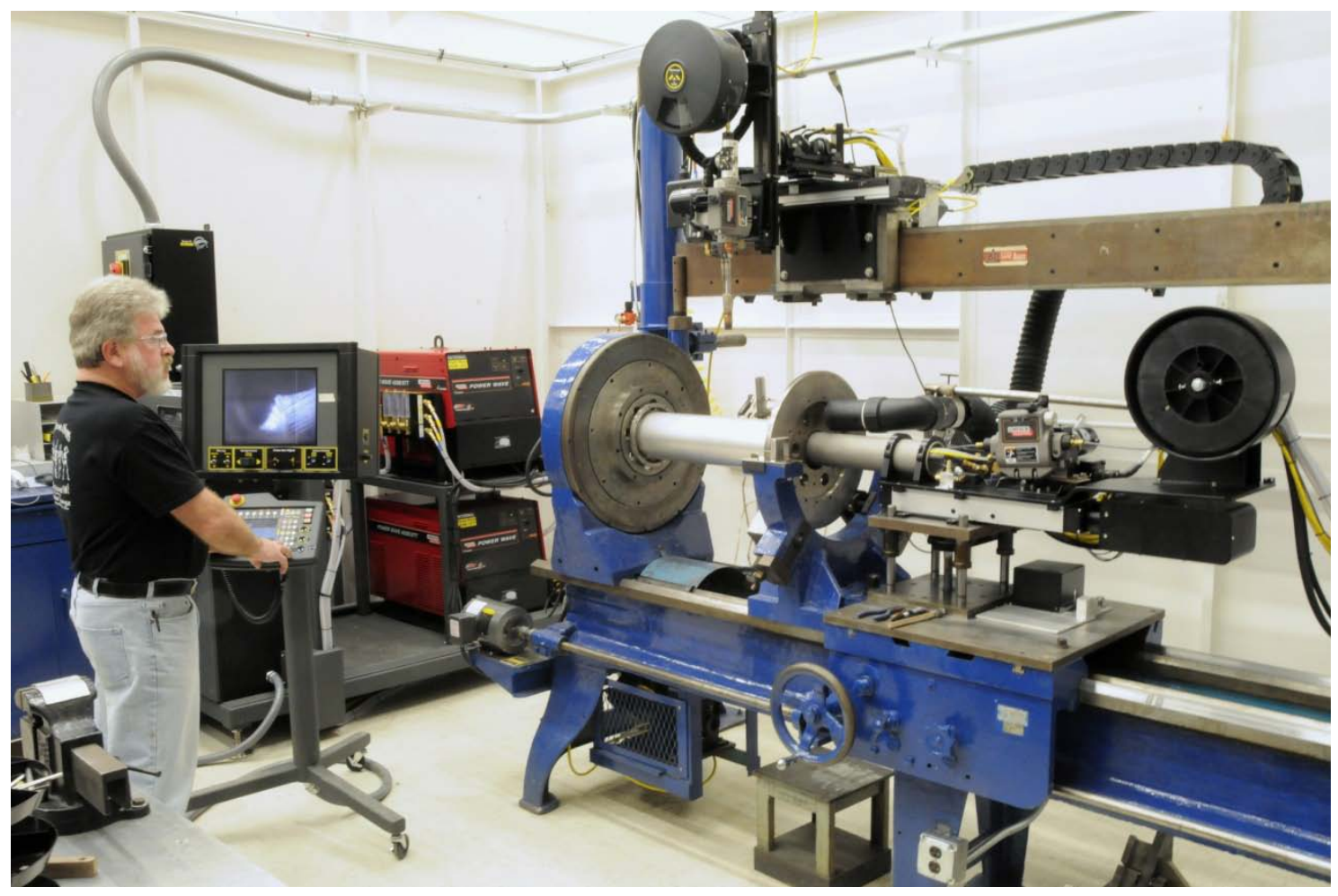

Fig. 13. Photograph of the upgraded HFIR welding system as installed at the B\&W/Lynchburg facilities. 


\section{NEW OUTER GAS METAL ARC WELDING HEAD}

The new outer GMA welding head is shown in Fig. 14. For the outer welding torch, a standard Lincoln model LN4610-35-5 torch was slightly modified for use. Fundamentally the new outer welding head is not significantly different than the old outer welding head. Some slight modifications were required to improve the feeding of the welding wire to the torch.

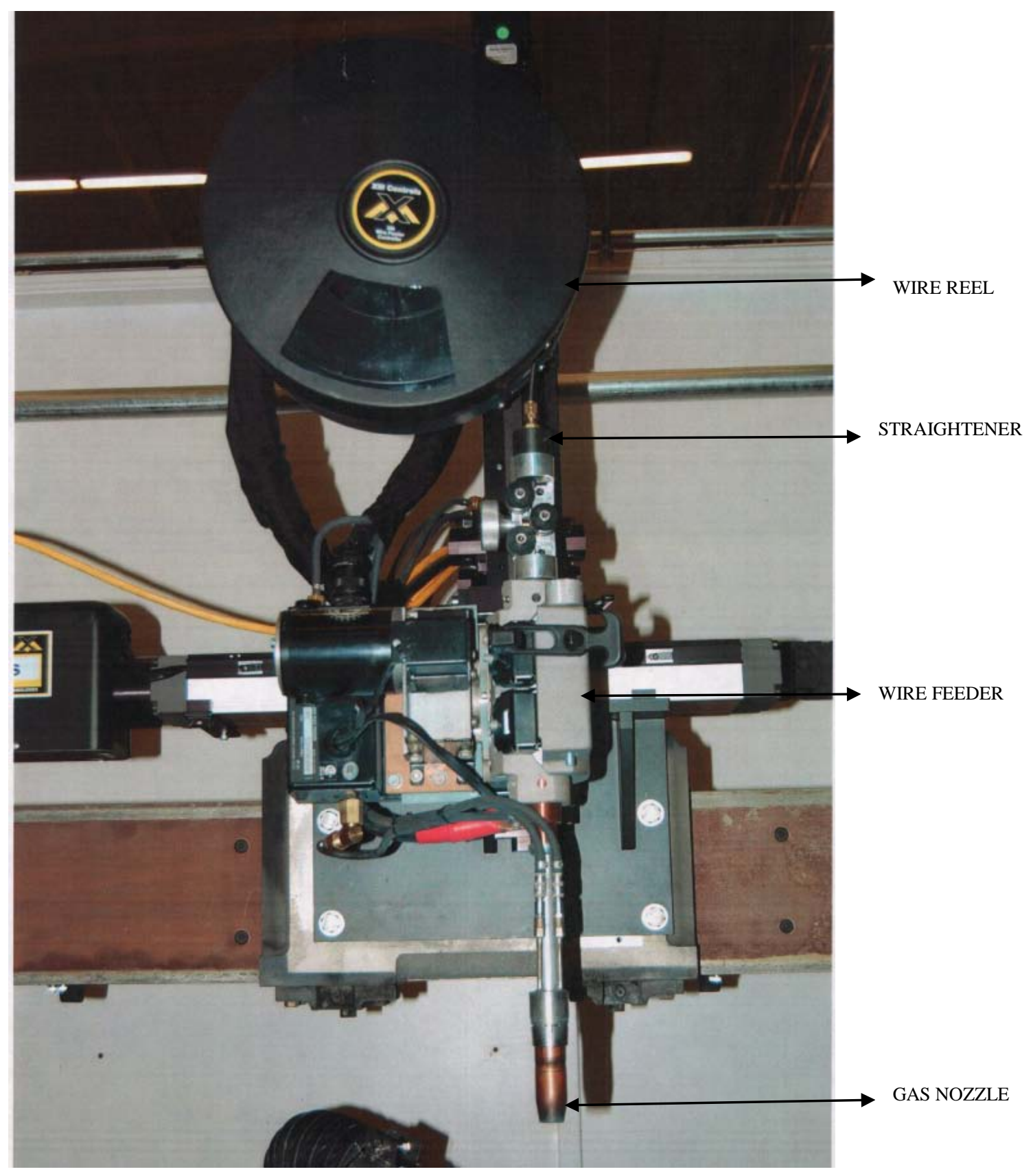

Fig. 14. New outer GMA welding head. 


\section{NEW INNER GAS METAL ARC WELDING HEAD}

The design of the new inner head consumed $\sim 9$ months, required several design iterations, and was not completed until after the inner welding head was returned to the factory in Idaho. On returning the inner head to AMET, the weld wire cast was changed from being in a plane perpendicular with the welding direction to being in a plane parallel with the welding direction. With the cast of the weld wire set parallel to the welding direction, the welding wire coming out of the contact tip is straight in the plane perpendicular to the welding direction. On returning the inner head to AMET, the contoured guide tube configuration was developed, incorporated into the inner welding head, and extensively arc tested over approximately a one-month period. During this period, several hundred minutes of arc testing were successfully performed in 5-6 minute intervals and procedures for reproducing and changing the contoured guide tube were developed.

For the inner welding head, the majority of the initial design effort centered on developing a welding head for reliably feeding the small diameter weld wire at the high rates required for the HFIR weld. The first design concept for the inner head was to use the standard Lincoln wire feeder with a "pull assist" wire feeder at the welding head near the contact tip. A significant effort in the second design iteration was in trying to improve and refine the "pull" assist wire feeder. During the arc testing of the second iteration of this design, it became apparent that the synchronization of the "push" and "pull” wire feeders at the high wire feed rates, particularly at the start of a weld, would be difficult to coordinate and the decision was made to test a "guide tube" design using just the Lincoln wire feeder without the "pull assist". This arc testing showed that the "guide tube" design provided better arc stability and was much simpler to implement in an effective manner. A cross section diagram of the initial guide tube design and close up photograph of this guide tube design with cover removed is shown in Fig. 15 and Fig, 16. Also shown in Fig. 16 is the disengaged "pull assist" mechanism that was tested along the guide tube design.

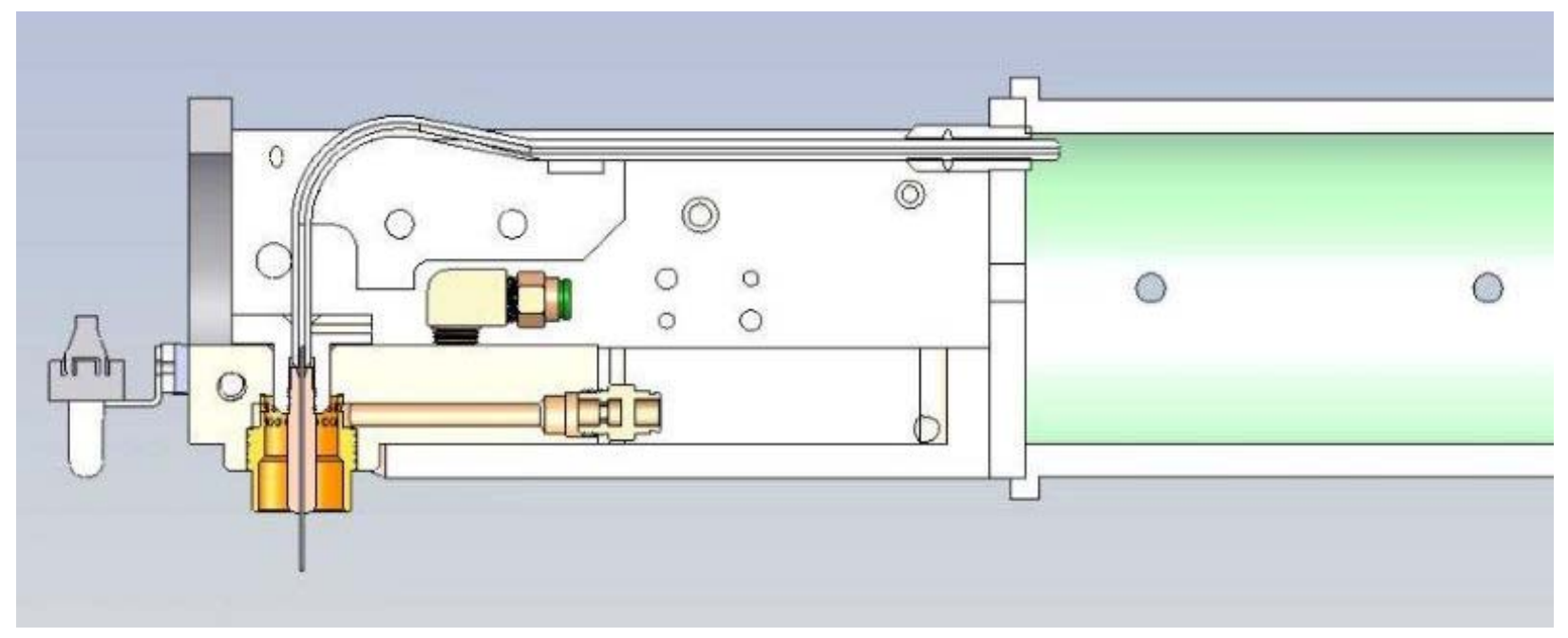

Fig. 15. Cross section of initial guide tube design. 


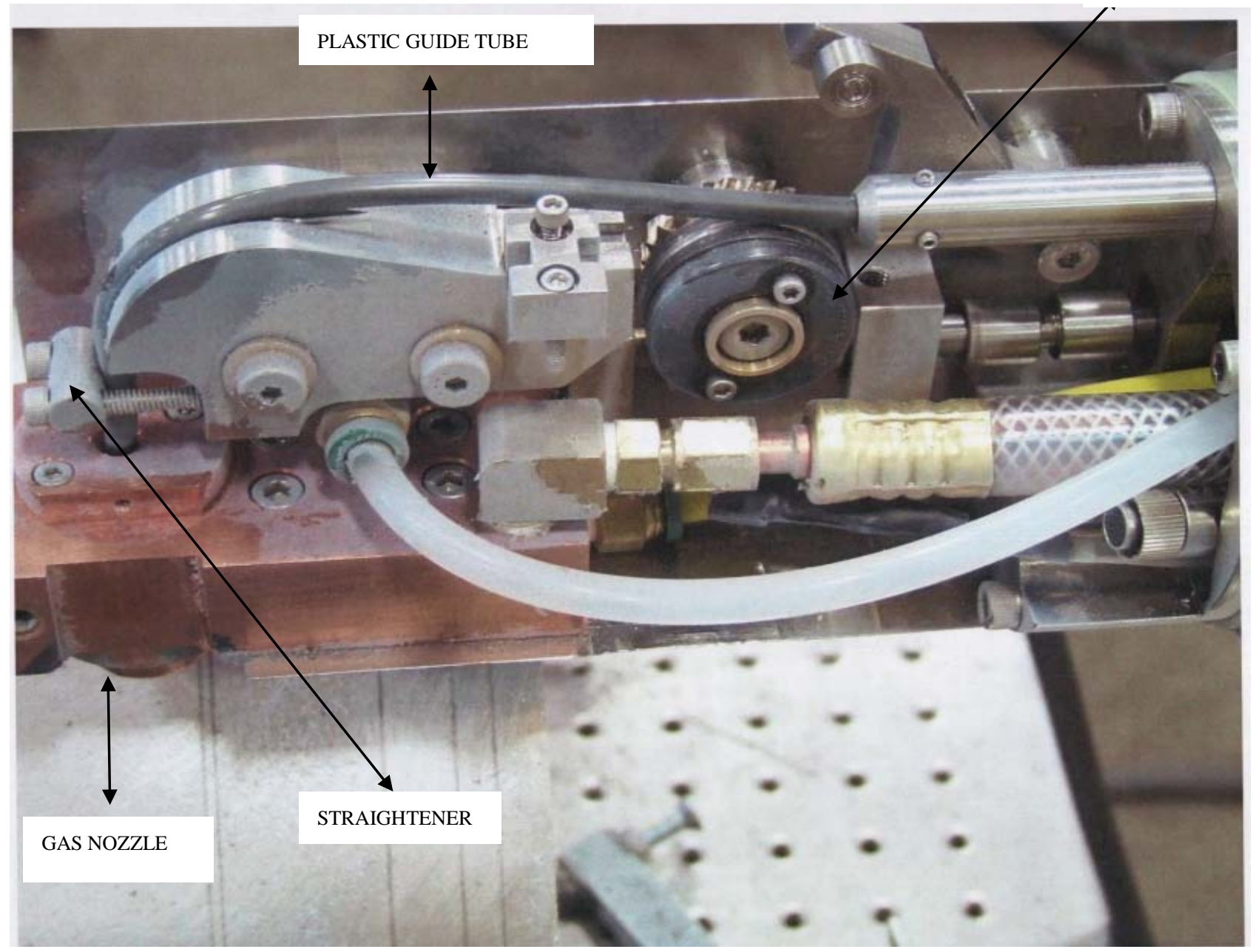

Fig. 16. Guide tube design showing pull assist disengaged.

At this point in the design process, a decision was made that the guide tube design would be the best route forward. In conjunction with the guide tube design, a method for straightening the weld wire by deflecting the plastic guide tube with a relatively small diameter bar pressed into the guide tube near the contact tip was incorporated (see Figs. 15 and 16). This method of wire straightening worked to some extent in short duration testing and the factory acceptance tests at AMET, but in operating the inner head in longer duration welding tests at B\&W, it was apparent that the inconsistencies in the drag resistance from the straightener would result in unreliable wire feeding.

In these welding tests, numerous instances were encountered where the weld wire would pile up in the wire feeder ("bird nesting"). Without the wire straightener, welding tests showed that the wire feeding with the guide tube design was consistent; however, it was obvious that the cast of the wire is set by the radius of the final $90^{\circ}$ bend. Using a wire straightener like the one used on the outer welding head before the Lincoln wire feeder had no effect. In the initial guide tube design without the wire straightener the wire case is $90^{\circ}$ to the welding direction and any resulting change in "stick out" of the weld wire will result in a change in the location of the melt pool. In welding HFIR fuel elements, uneven weld metal fill in the weld groove will result in variations in weld penetration and reportable defects in the resulting welds due to under fill. 
Welding on the No. 3 side plate (inside weld) where the operator can see and adjust the torch head position during welding, some curvature in the weld wire perpendicular to the welding direction might be accommodated. However, in a "blind" weld as is required in the No. 1 side plate, it was apparent the weld wire must be straight in the plane perpendicular with welding direction to make a consistent weld. Changing the cast in the weld wire to be in a plane parallel with the welding direction accomplished this objective.

The innovative breakthrough in the new inner torch design is the way the direction of the cast in the 0.762 mm diameter (0.030-inch) aluminum weld wire is changed to be in a plane parallel with welding direction without creating any significant drag resistance in feeding the weld wire. In a confined space torch, a conventional wire straighter cannot be used and the final $90^{\circ}$ bend establishes the cast of the weld wire that will emerge from the contact tip unless the contact tip is bent (as in old inner torch) or some other device is used to straighten the weld wire. With a "pull" wire feeder at the welding torch because of space limitations, bending the contact tip is about the only option available. The change in direction of the wire cast in the guide tube head design was accomplished within the $101.6 \mathrm{~mm}$ diameter (4 inches) envelope of the welding head by bringing the weld wire in from one side and making the final $90^{\circ}$ bend on a relatively large radius of curvature to set the wire cast parallel to the welding direction.

Top views of the contoured guide tube inner welding head with the protective cover removed are shown in Fig. 17 and Fig. 18.

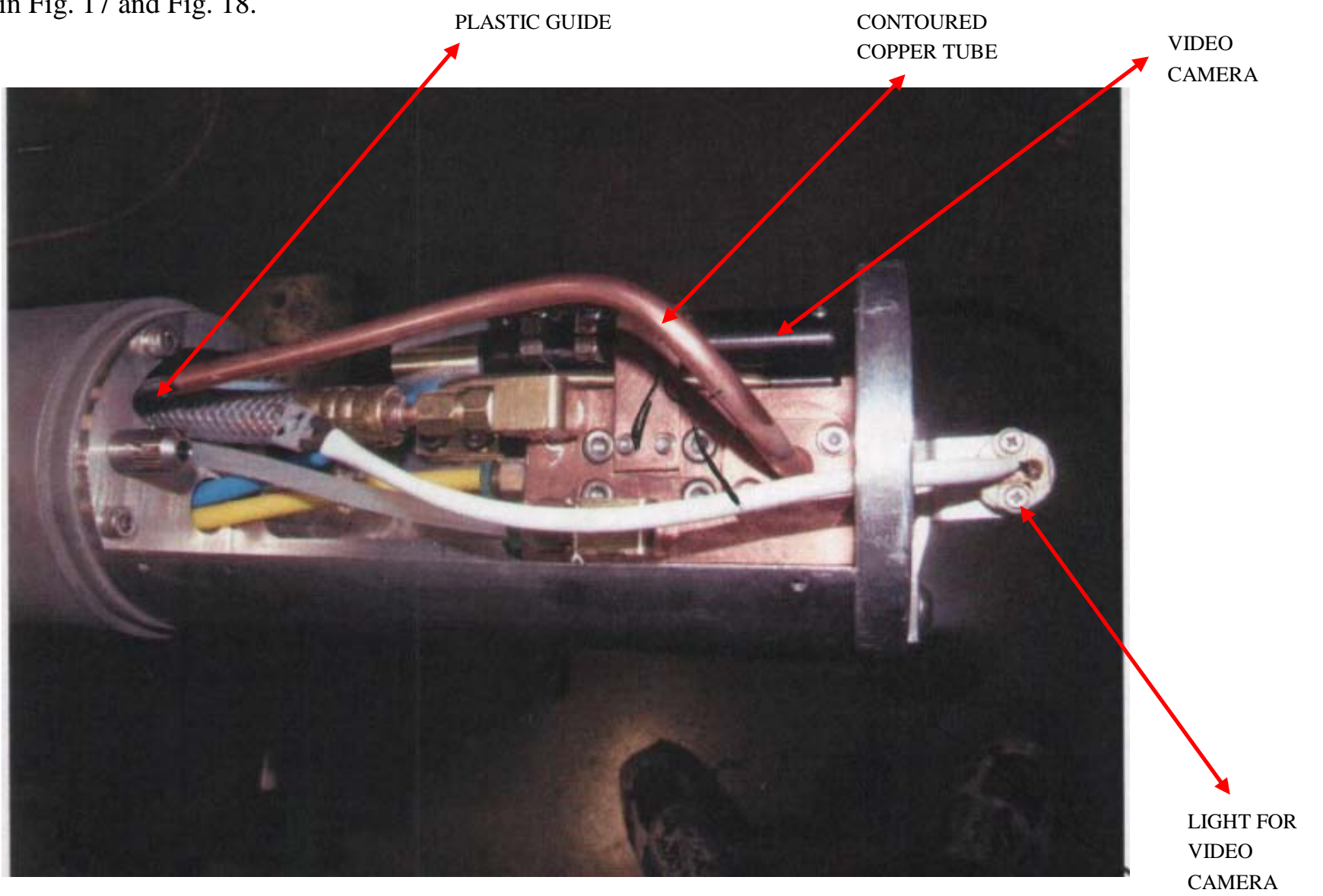

Fig. 17. Top views of guide tube design with protective cover removed. 


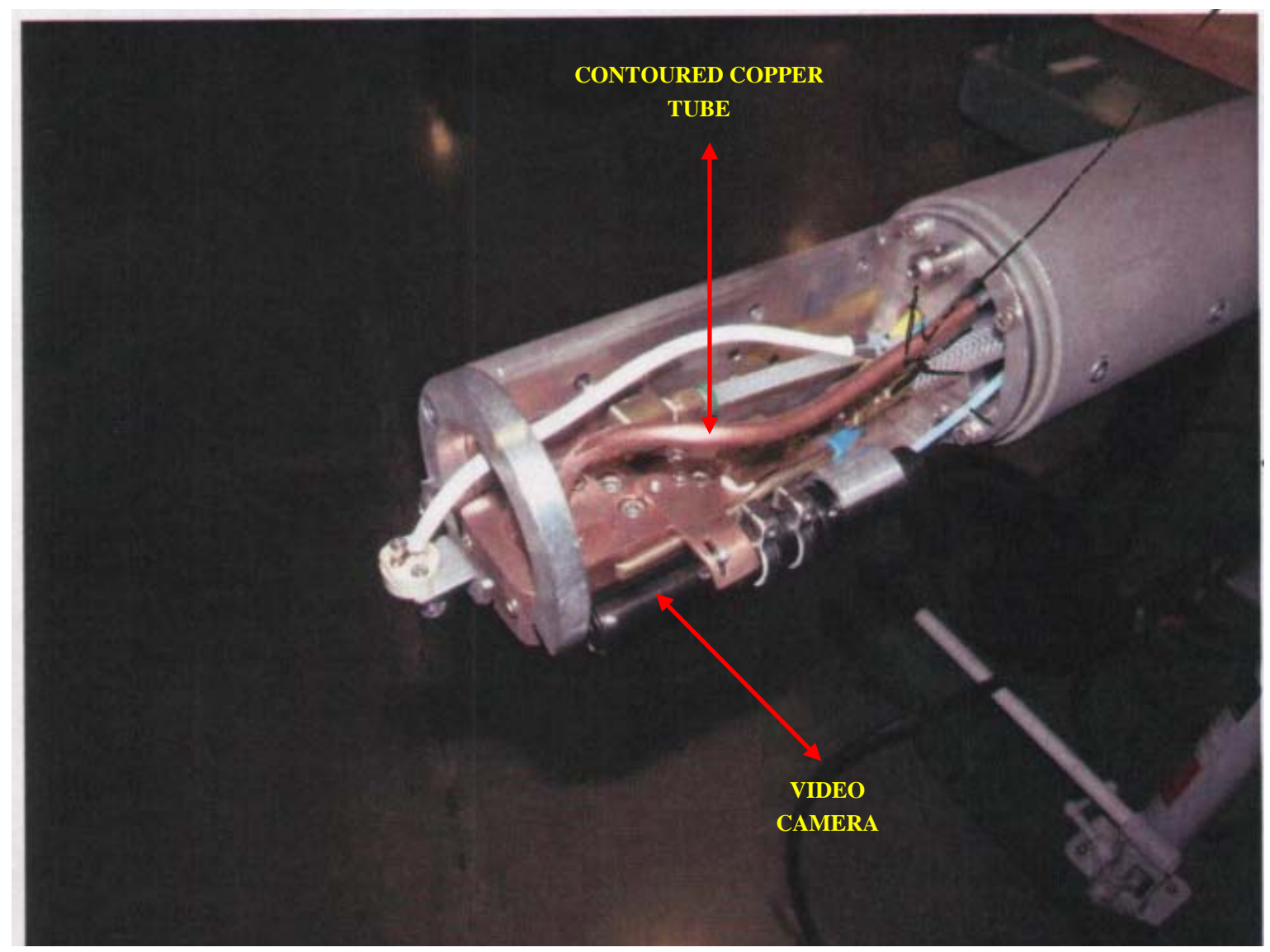

Fig. 18. Top views of contoured guide tube design with protective cover removed.

As shown, a relatively large radius of curvature in the bend is used to minimize drag resistance on the small diameter wire to prevent "bird nesting" at feed rates up to $\sim 0.3 \mathrm{~m} / \mathrm{s}$ (700 inches per minute). The weld wire, as it emerges in the new guide tube design from the contact tip in the parallel and perpendicular planes with the welding direction, is shown in Figs. 19 and Fig. 20. As shown, the weld wire from the contact tip is essentially straight in the plane perpendicular to the welding direction. The slight curvature in the wire parallel with the welding direction as shown in Fig. 20 can be easily accommodated by the welder power controller for variations in "stick out." This innovation allowed the use of a standard "push" wire feeder through a plastic guide tube and standard straight contact tips and represents a significant simplification and improvement compared to the original design. Another advantage of the new torch design because the wire is straight perpendicular to the welding direction is that the torch head can be mechanically aligned to the centerline of the weld groove without visual verification of the weld wire position. This represents another simplification and a potential improvement in the quality of the welds with the new welding head design.

The use of copper tube bent in the required configuration to shape the plastic guide tube is another innovation in the contoured guide tube design. This shaping of the plastic guide tube is accomplished by sliding a guide tube inside a copper tube bent in the required configuration. The jig used to shape the contour of the copper tubing used in the contoured guide tube design is shown in Fig. 21. 


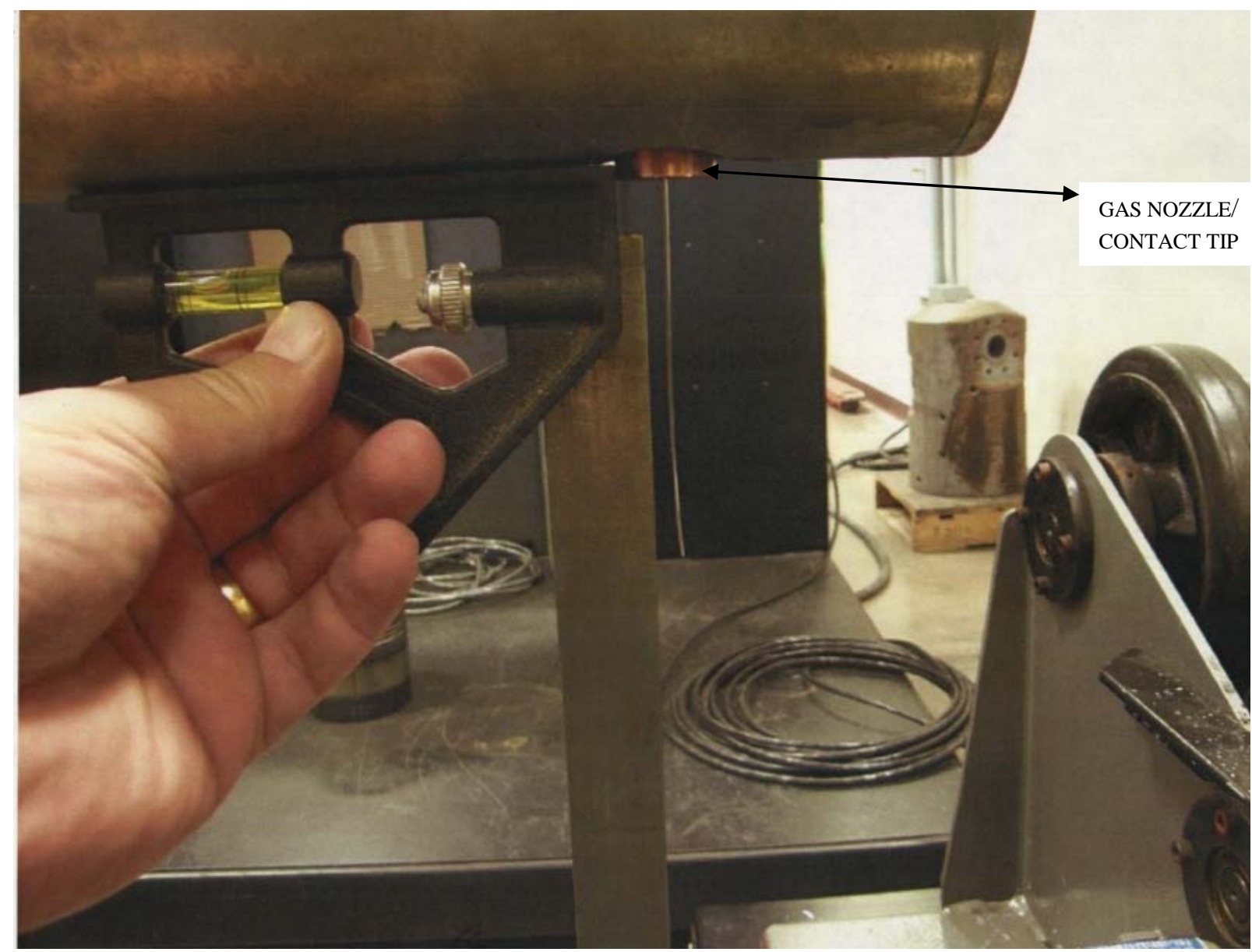

Fig. 19. Weld wire perpendicular to welding direction.

In initial arc-testing at $\mathrm{B} \& \mathrm{~W}$ of the inner welding head before implementation of the contoured guide tube design and when the weld wire feeder was functioning, the welding sounded uniform with minimum sputtering or popping indicative of good vapor transfer of weld metal. The resulting weld metal deposits were uniform and showed that the inert gas coverage was good. The new heat sink power block and inert gas coverage (gas cup) functioned as designed. These components were based on the old inner welding head but represented a significant simplification compared to the original inner welding head not considering the complexity of weld wire "pull" drive assembly used in the original inner welding head design. The use of a single piece copper block with crossed drilled and plugged holes for water cooling provides better water cooling than the old water cooled power block design and is much simpler than the multiple pieces and O-ring seals used in the original inner welding head. The treaded single piece copper gas cup and inert gas diffuser was based to some extent on the original inner welding head design and provides excellent inert gas cover. This single piece inert gas diffuser and gas cup is shown in Fig. 22. The standard treaded contact tip used in both inner and outer welding heads is shown in Fig. 23. 


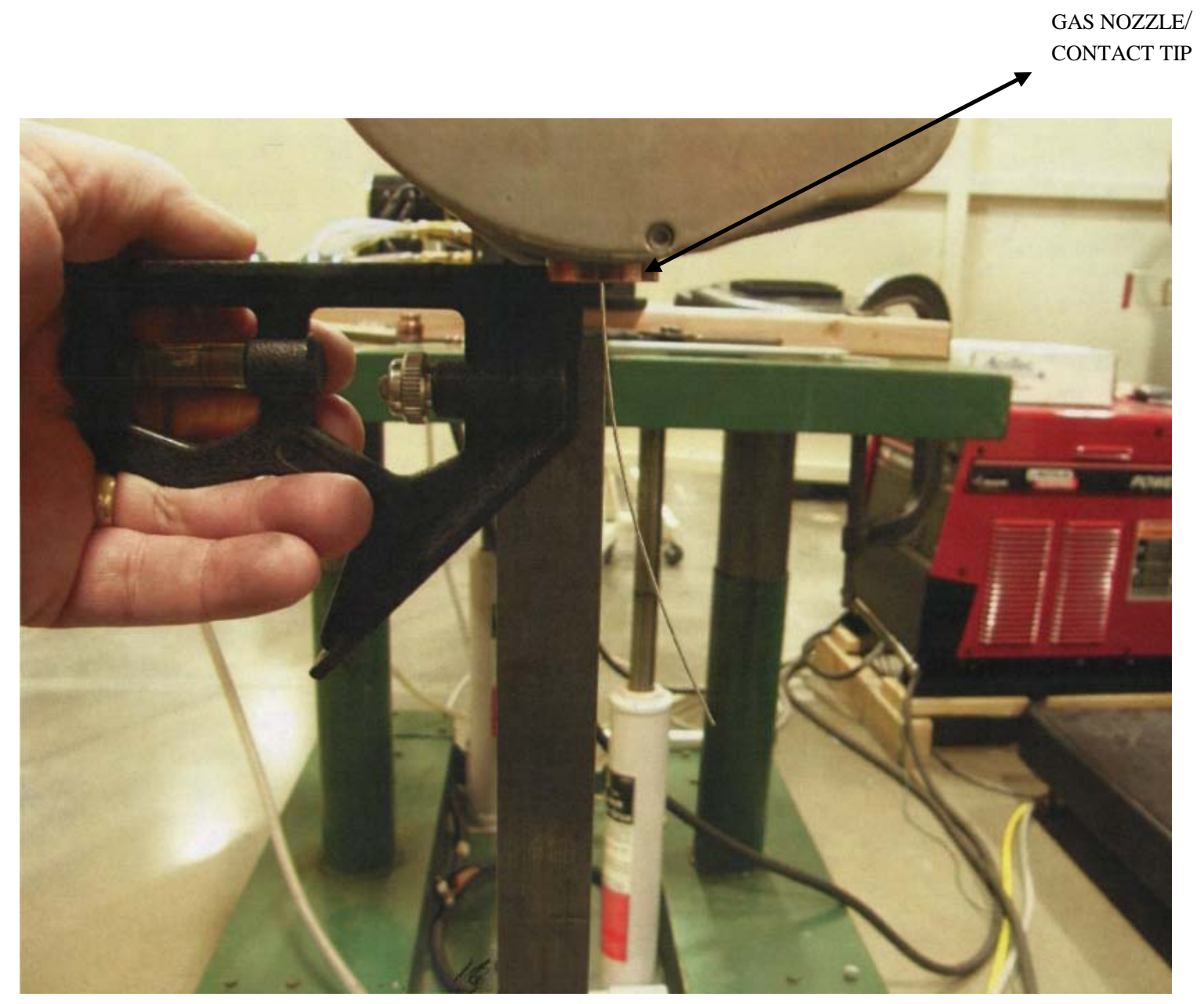

Fig. 20. Weld wire parallel to welding direction.

Changing of the contact and gas cup/diffuser and contact tips are simple twist operations. An overview of the inner welding head installed in Lynchburg is shown in Fig.24.

In developing the new inner welding head, a considerable effort was spent in incorporating a video camera (Figs. 17 and 18) into the new inner welding head. The need for this video camera was based on the need of observing the weld wire position and adjusting the contact tip on the original inner weld head design. In the new contoured guide tube design, the wire emerging from the contact tip is essentially straight in a plane perpendicular to the welding direction and, as a result, the torch can be mechanically aligned to the centerline of weld groove without visual observations of the weld wire position. This represents a simplification and a potential improvement in the quality of the welds with the new inner welding head design. In the future, the video camera in the new contoured guide tube design will likely now be used as a secondary quality-control verification of the weld head position instead of having to be an essential part to executing the manual control of the positioning of the weld wire. 


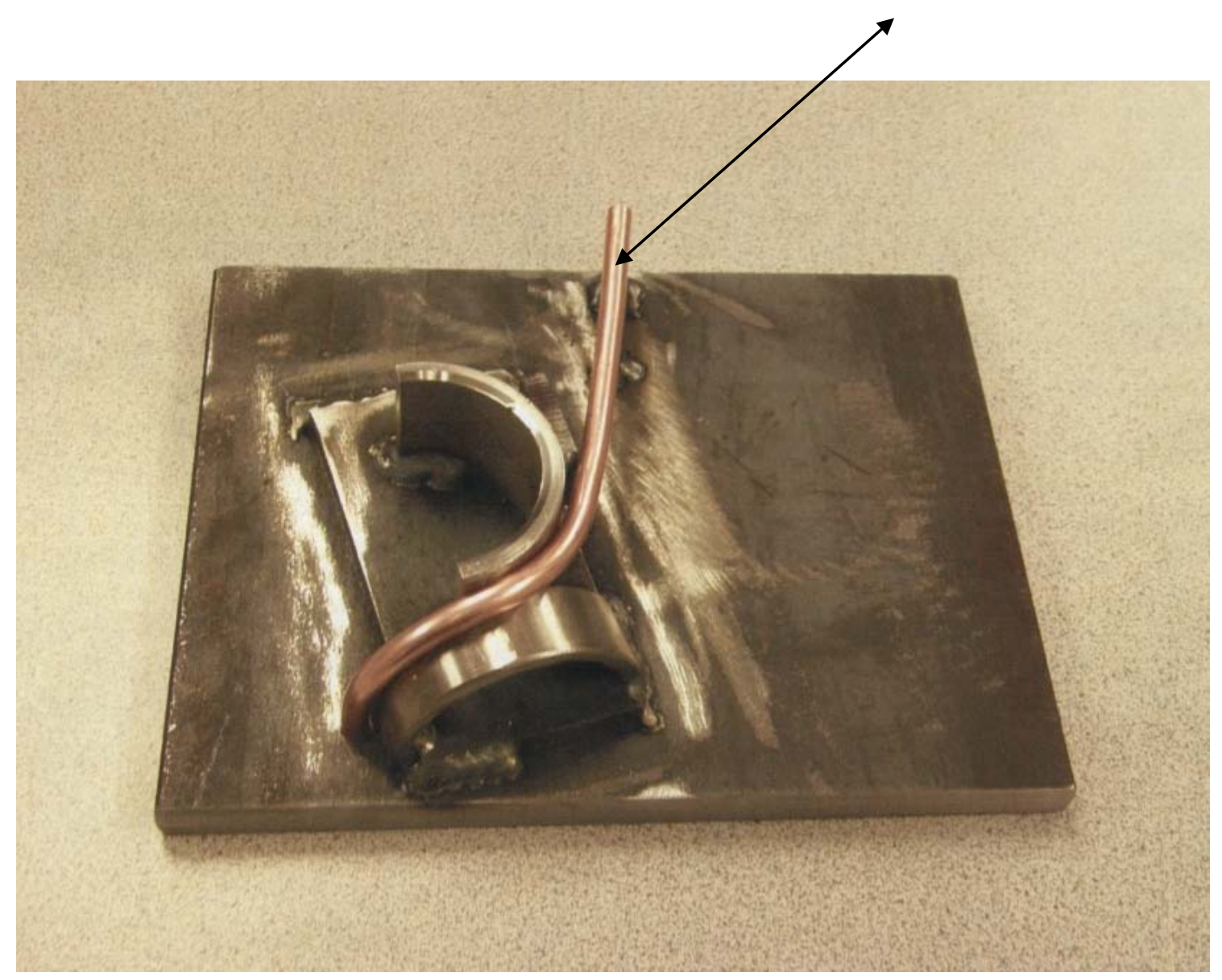

Fig. 21. Jig used to shape contour of copper tubing. 


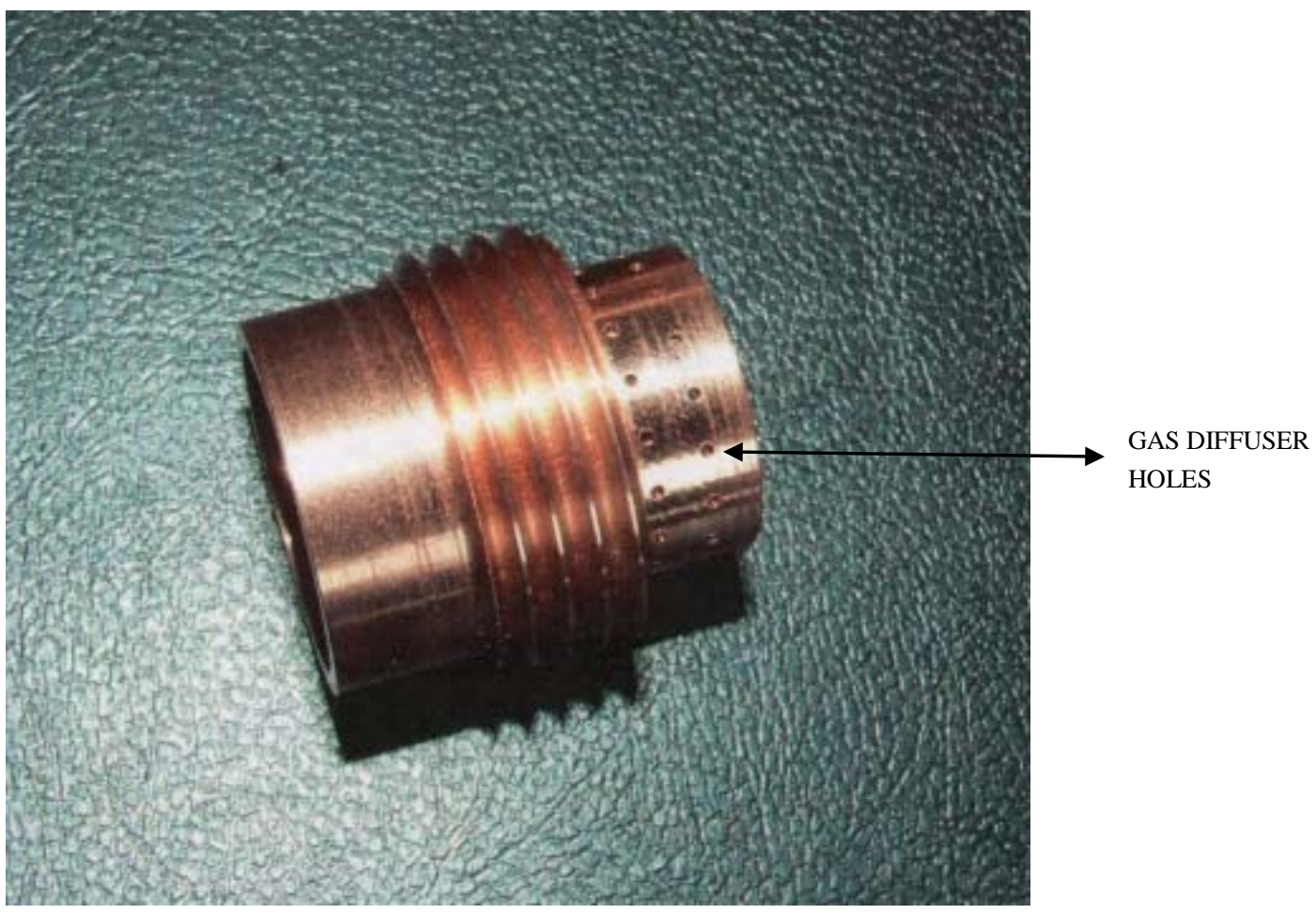

Fig. 22. Copper gas diffuses inert gas cup.

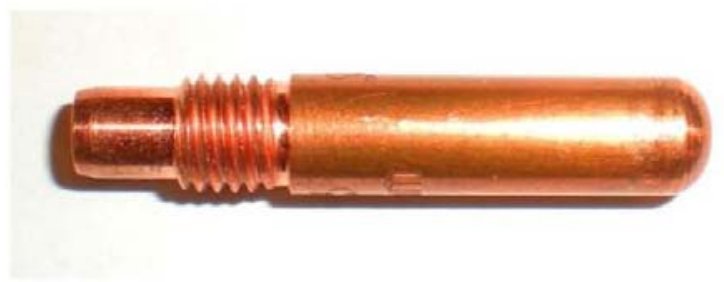

Fig.23. The standard screw threaded contact tip used in inner and outer welding torches. 


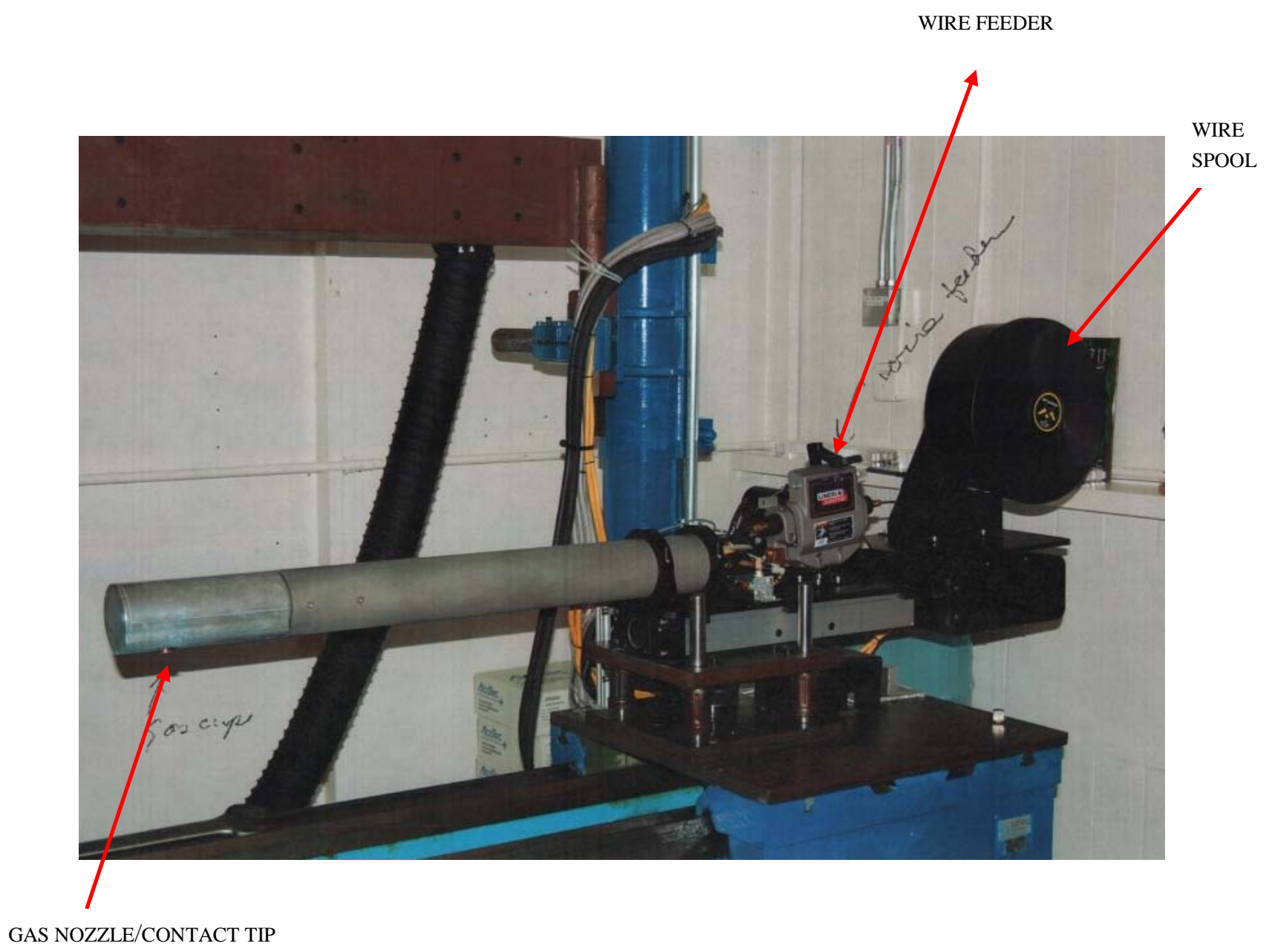

Fig. 24. Inner welding head installed at B\&W Lynchburg, Virginia facilities. 


\section{CONCLUSIONS}

The upgraded HFIR welding system represents a major improvement in the system used in welding HFIR fuel elements. The new inner GMAW torch is capable of welding a $121 \mathrm{~mm}$ (4.75 inches) inside diameter aluminum tube that is up to $0.61 \mathrm{~m}$ (24-inches) in length and is a significant advancement over the GMAW torch that has been used for the previous 40 years to weld the HFIR element side plates.

The innovative breakthrough in the new inner torch design is the modification to the previous design so that the direction of the cast using the $0.762 \mathrm{~mm}(0.030$-inch) diameter aluminum weld wire is changed so that the weld wire from the contact tip is straight in the plane perpendicular to the welding direction without creating any significant drag resistance in feeding the weld wire. The change in direction of the wire cast in the guide tube welding head design was accomplished within the $101.6 \mathrm{~mm}$ (4 inches) diameter envelope of the welding head by feeding the weld wire from one side and making the final $90^{\circ}$ bend on a relatively large radius of curvature in order to set the wire cast parallel to the welding direction. As a result in the contoured guide tube design, the weld wire emerges from the contact tip is straight in the plane perpendicular to the welding direction. The slight curvature in the weld wire in the plane parallel to the welding direction can be readily accommodated by the automatic welding power supply controller for variations in "stick out." Another innovation is the use of copper tube bent in the required configuration to shape the plastic guide tube. 


\section{REFERENCES}

1. J. W. Tackett, J. H. Erwin, C.F. Leitten, Jr., and G. M. Slaughter, “Assembly and Welding Development for the High Flux Isotope Reactor Fuel Element,” Research Reactor Fuel Element Conference, Gatlinburg, Tenn. , September 17-19, 1962, USAEC-TID-7642, Book 1, pages 290-314.

2. G. M. Adamson, Jr., and R. W. Knight, HFIR Fuel Element Production and Operation, ORNL/TM2196, Oak Ridge National Laboratory, Oak Ridge, TN, June 1968, http://www.ornl.gov/info/reports/1968/3445600496657.pdf. 


\section{APPENDIX A}

\section{SUMMARY OF REQUIREMENTS FOR UPGRADING HFIR WELDING SYSTEM}

\begin{tabular}{|c|c|}
\hline Component & Requirement \\
\hline \multicolumn{2}{|l|}{ Inner welding head } \\
\hline Diameter of welding head — maximum & 4 in. $(102 \mathrm{~mm})$ \\
\hline $\begin{array}{l}\text { Welding torch for GMAW with inert gas flow controls- } \\
\text { water cooled }\end{array}$ & Special design capable of $300 \mathrm{amp}$ \\
\hline $\begin{array}{l}\text { Wire feeder with straighter — integrated with weld } \\
\text { controller }\end{array}$ & $\begin{array}{l}\text { Lincoln model 10R w straighter or } \\
\text { equivalent }\end{array}$ \\
\hline Welding power supply & $\begin{array}{l}\text { Lincoln model } 455 \text { STT R or } \\
\text { equivalent }\end{array}$ \\
\hline $\begin{array}{l}\text { Torch } \boldsymbol{x} \text { - and } \boldsymbol{y} \text {-axis precision servo integrated with weld } \\
\text { controller }\end{array}$ & $\begin{array}{l}\text { Accurate to } \pm 0.002 \text { in. } \forall 0.051 \mathrm{~mm}) \text {, } \\
\text { min. travel capacity of } 0.1^{\prime}(2.54 \mathrm{~mm})\end{array}$ \\
\hline Arc oscillation ( $x$ axis) integrated with weld controller & Yes \\
\hline Video camera to aid positioning torch (existing camera) & Yes \\
\hline Mounting — existing lathe slide or new $\boldsymbol{x}-\boldsymbol{y}$ slides & Option \\
\hline $\begin{array}{l}\text { Torch } \boldsymbol{x} \text { axis slide — adjustable and lockable (new or mod. } \\
\text { existing) }\end{array}$ & $\begin{array}{l}0-48 \text { in. }(0-1.22 \mathrm{M}), \forall 0.015 \text { in. }(0.381 \\
\text { mm) or comparable std. }\end{array}$ \\
\hline $\begin{array}{l}\text { Torch } \boldsymbol{y} \text { axis slide — adjustable and lockable (new or mod. } \\
\text { existing) }\end{array}$ & $\begin{array}{l}0 \text { - } 18 \text { in. (0- } 457 \mathrm{~mm}), \forall 0.015 \text { in.; } \\
\text { ( } \forall 0.381 \mathrm{~mm}) \forall 15^{\circ} \text { or comparable std. }\end{array}$ \\
\hline Electrical — weld head electrically isolated from ground & Ground isolation $>1$ Mohm \\
\hline \multicolumn{2}{|l|}{ Outer Welding Head } \\
\hline $\begin{array}{l}\text { Welding torch for GMAW with inert gas flow controls - } \\
\text { water cooled }\end{array}$ & $\begin{array}{l}\text { Lincoln model LN4610-35-5 or } \\
\text { equivalent }\end{array}$ \\
\hline $\begin{array}{l}\text { Wire feeder with straighter — integrated with weld } \\
\text { controller }\end{array}$ & $\begin{array}{l}\text { Lincoln model 10R w straighter or } \\
\text { equivalent }\end{array}$ \\
\hline Welding power supply & $\begin{array}{l}\text { Lincoln model } 455 \text { STT R or } \\
\text { equivalent }\end{array}$ \\
\hline $\begin{array}{l}\text { Torch } \boldsymbol{x} \text { - and } \boldsymbol{y} \text {-axis precision servo integrated with weld } \\
\text { controller }\end{array}$ & $\begin{array}{l}\text { Accurate to } \pm 0.002 \text { in. }(\forall 0.051 \mathrm{~mm}) \text {, } \\
\text { min. travel capacity of } 0.1 \mathrm{in.}(2.54 \\
\mathrm{mm})\end{array}$ \\
\hline Arc oscillation ( $x$ axis) integrated with weld controller & Yes \\
\hline Mounting - existing pedestal or new $\boldsymbol{x}$ - $\boldsymbol{y}$ slide & Option \\
\hline $\begin{array}{l}\text { Torch } \boldsymbol{x} \text { axis slide — adjustable and lockable (new or mod. } \\
\text { existing) }\end{array}$ & $\begin{array}{l}0-48 \text { in. }(0-1.22 \mathrm{M}), \forall 0.015 \text { in. } \\
\text { ( } \forall 0.381 \mathrm{~mm}) \text { or comparable std.. }\end{array}$ \\
\hline $\begin{array}{l}\text { Torch } \boldsymbol{y} \text { axis slide — adjustable and lockable (new or mod. } \\
\text { existing) }\end{array}$ & $\begin{array}{l}0-18 \text { in. (0- } 457 \mathrm{~mm}), \forall 0.015 \text { in.; } \\
\text { ( } \forall 0.381 \mathrm{~mm}) \forall 15^{\circ} \text { or comparable std. }\end{array}$ \\
\hline Electrical — weld head electrically isolated from ground & Ground isolation $>1 \mathrm{Mohm}$ \\
\hline
\end{tabular}


Appendiz A (continued)

Rotating Device of Al Pipe (fuel elements) for Welding

\begin{tabular}{l|l}
\hline Tooling interface & Required \\
\hline Maximum weight to rotate & $300 \mathrm{lb}$ ( 136 kg) \\
\hline Rotating head - new or modify existing lathe head & Option \\
\hline Electrical - pipe to be electrically grounded during rotation & Required \\
\hline Pipe OD welding capability & 9 in. $(229 \mathrm{~mm})$ to 19 in. $(483 \mathrm{~mm})$ \\
\hline Pipe ID welding capability & 4.25 in. $(108 \mathrm{~mm})$ to 12 in. $(305 \mathrm{~mm})$ \\
\hline Overall pipe length welding capability & 36 in. $(914 \mathrm{~mm})$ \\
\hline Rotational speed variable integrated with weld controller & $0-6 \mathrm{rpm}(0-0.63$ radians/second $)$ \\
\hline Programmable Power Supply Controller & Special design \\
\hline Operator Pendent & Special design \\
\hline Data Acquisition & Option \\
\hline Industrial Control Skid & Special design \\
\hline
\end{tabular}




\section{INTERNAL DISTRIBUTION}

1. K. J. Beierschmitt (beierschmitt@ornl.gov)

2. C. A. Blue (blueca@ornl.gov)

3. S. E. Burnette (burnettese@ornl.gov)

4. R. A. Crone (cronera@ornl.gov)

5. J. H. Miller (millerjh2@ornl.gov)
6.

7.

8.

9.

10.
D. L. Pinkston (pinkstondl@ornl.gov)

R. T. Primm III (primmrtiii@ornl.gov)

J. D. Sease (seasejd@ornl.gov)

S. J. Zinkle (zinklesj@ornl.gov)

ORNL Laboratory Records (hamrindr@ornl.gov)

\section{EXTERNAL DISTRIBUTION}

11. W. C. Richardson, B\&W, 2016 Mount Athos Rd., Lynchburg, VA 24504 (WCRichardson@bwxt.com).

12. Howard Harvey B\&W, 2016 Mount Athos Rd., Lynchburg, VA 24504 (hdharvey@babcock.com).

13. Robert Ostrowski, B\&W, 2016 Mount Athos Rd., Lynchburg, VA 24504 (RTOstrowski@babcock.com).

14. D. Dombrowski, Los Alamos National Laboratory, (ddombrow@lanl.gov). 